\title{
Modeling study of the 2010 regional haze event in the North China Plain
}

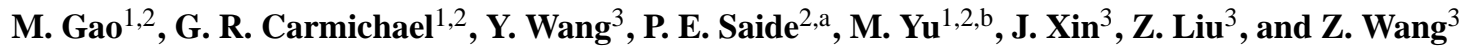 \\ ${ }^{1}$ Department of Chemical and Biochemical Engineering, University of Iowa, Iowa City, IA, USA \\ ${ }^{2}$ Center for Global and Regional Environmental Research, University of Iowa, Iowa City, IA, USA \\ ${ }^{3}$ State Key Laboratory of Atmospheric Boundary Layer Physics and Atmospheric Chemistry, Institute \\ of Atmospheric Physics, Chinese Academy of Sciences, Beijing, China \\ anow at: Atmospheric Chemistry observations and Modeling (ACOM) lab, National Center for Atmospheric \\ Research (NCAR), Boulder, CO, USA \\ ${ }^{b}$ now at: Mathematics and Computer Science Division, Argonne National Laboratory, Argonne, IL, USA
}

Correspondence to: M. Gao (meng-gao@uiowa.edu) and G. R. Carmichael (gcarmich@engineering.uiowa.edu)

Received: 7 June 2015 - Published in Atmos. Chem. Phys. Discuss.: 26 August 2015

Revised: 29 January 2016 - Accepted: 2 February 2016 - Published: 12 February 2016

\begin{abstract}
The online coupled Weather Research and Forecasting-Chemistry (WRF-Chem) model was applied to simulate a haze event that happened in January 2010 in the North China Plain (NCP), and was validated against various types of measurements. The evaluations indicate that WRFChem provides reliable simulations for the 2010 haze event in the NCP. This haze event was mainly caused by high emissions of air pollutants in the NCP and stable weather conditions in winter. Secondary inorganic aerosols also played an important role and cloud chemistry had important contributions. Air pollutants outside Beijing contributed about $64.5 \%$ to the $\mathrm{PM}_{2.5}$ levels in Beijing during this haze event, and most of them are from south Hebei, Tianjin city, Shandong and Henan provinces. In addition, aerosol feedback has important impacts on surface temperature, relative humidity (RH) and wind speeds, and these meteorological variables affect aerosol distribution and formation in turn. In Shijiazhuang, Planetary Boundary Layer (PBL) decreased about $278.2 \mathrm{~m}$ and $\mathrm{PM}_{2.5}$ increased more than $20 \mu \mathrm{g} \mathrm{m}^{-3}$ due to aerosol feedback. It was also shown that black carbon (BC) absorption has significant impacts on meteorology and air quality changes, indicating more attention should be paid to $\mathrm{BC}$ from both air pollution control and climate change perspectives.
\end{abstract}

\section{Introduction}

The North China Plain (NCP) is one of the most densely populated areas in the world and it has been the Chinese center of culture and politics since early times. Beijing, the capital of China, Tianjin, Shijiazhuang and other big cities with active economic developments are located in the NCP. This region is experiencing heavy haze pollution with record-breaking high concentrations of particulate matters (L. T. Wang et al., 2014). Haze is defined as an air pollution phenomenon where horizontal visibility is less than $10 \mathrm{~km}$ caused by aerosol particles, such as dust and black carbon (BC), suspended in the atmosphere (Tao et al., 2012). Its formation is highly related to meteorological conditions, emissions of pollutants and gas-to-particle conversion (Sun et al., 2006; Watson, 2002). Haze has attracted much attention for its adverse impacts on visibility and human health. During haze periods, reduced visibility affects land, sea and air traffic safety and the fine particles can directly enter the human body and adhere to lungs to cause respiratory and cardiovascular diseases (Liu et al., 2013). Moreover, haze affects climate and ecosystems via aerosol-cloud-radiation interactions (Sun, et al., 2006; Liu et al., 2013).

Because haze influences visibility, human health and climate (Gao et al., 2015), numerous studies have used multiple methods to investigate physical, chemical and seasonal characteristics of aerosols during haze. The increase of secondary inorganic aerosols is considered to be an attribute of 

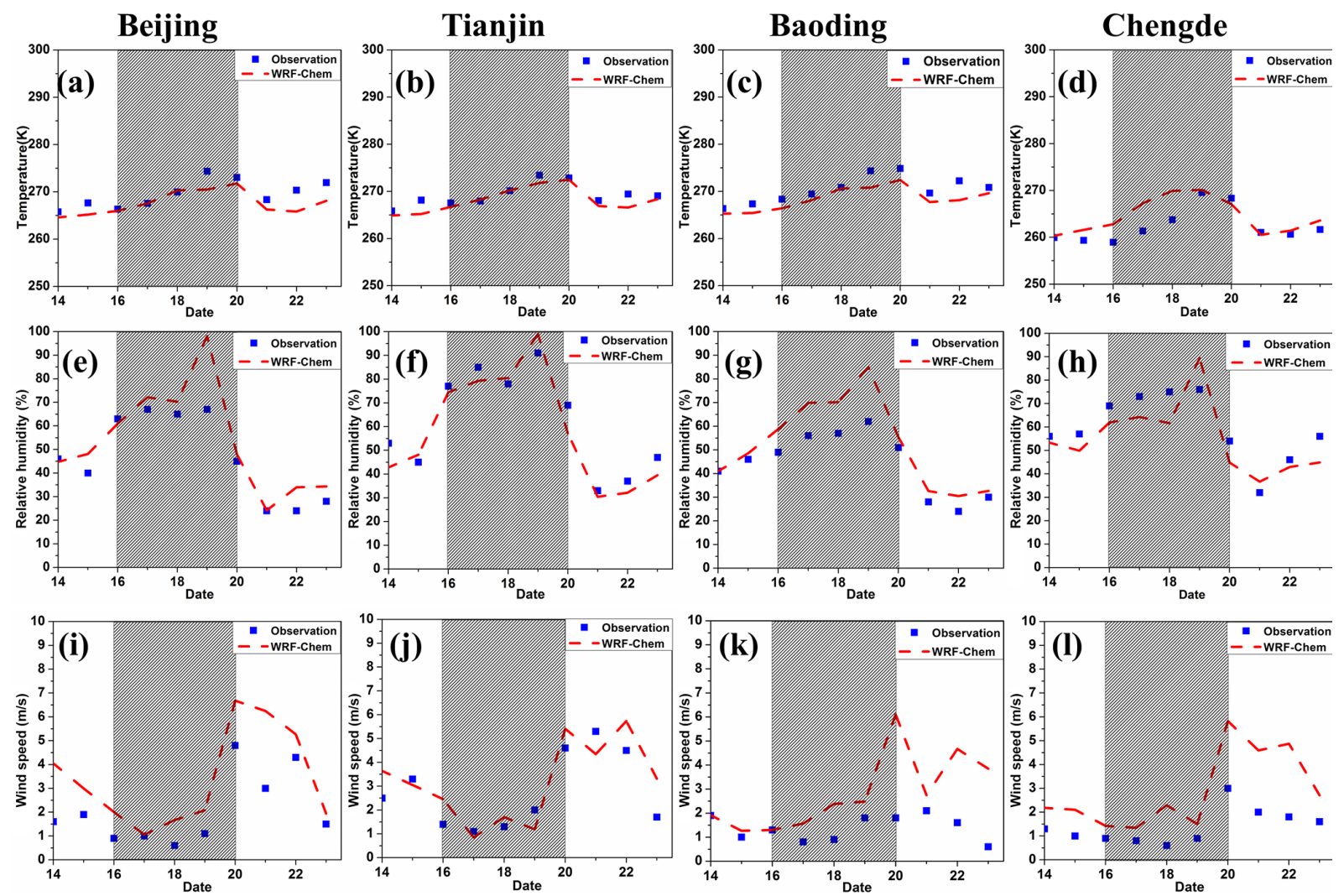

Figure 1. The temporal variations of observed and simulated $24 \mathrm{~h}$ average temperature (a-d), relative humidity (e-h) and wind speed (i-l) in the Beijing, Tianjin, Baoding, and Chengde stations.

the haze pollution in east China (Tan et al., 2009; Zhao et al., 2013). Tan et al. (2009) studied the characteristics of aerosols in non-haze and haze days in Guangzhou, China and found that secondary pollutants $\left(\mathrm{OC}, \mathrm{SO}^{2-}, \mathrm{NO}^{3-}\right.$ and $\mathrm{NH}^{4+}$ ) were the major components of haze aerosols and they showed a remarkable increase from non-haze to haze days. Similar conclusions were drawn by Zhao et al. (2013) after studying the chemical characteristics of haze aerosols in the NCP. Secondary Organic Aerosol (SOA) formation can also be significant during haze (Tan et al., 2009; Zhao et al., 2013). Studies of aerosol optical properties show that finemode aerosols were dominant during haze (Yu et al., 2011; Li et al., 2013). In addition, contributions of diverse factors to haze formation, such as biomass burning and regional transport, have been investigated. Chen et al. (2007) used MM5CMAQ to reproduce the haze pollution in September 2004 in the Pearl Region Delta (PRD) region and discovered that sealand breeze played an important role. Wang et al. (2009) discovered that almost 30-90\% of the organics during the haze happened in June 2007 in Nanjing were from wheat straw burning. Cheng et al. (2014) concluded that biomass burning could cause haze issues and they found biomass burning contributed $37 \%$ of $\mathrm{PM}_{2.5}, 70 \%$ of Organic Carbon (OC) and $61 \%$ of Elemental Carbon (EC) based upon both model- ing and measurement results of case study in summer 2011 in the Yangtze River Delta (YRD) region. These biomass burning events mainly occurred in summer and autumn in east and south China (Cheng et al., 2013, 2014; Li et al., 2010; Wang et al., 2007, 2009). To evaluate regional contributors to the haze in southern Hebei, Wang et al. (2012) simulated the time period from 2001 to 2010 and concluded that Shanxi province and the northern Hebei were two major contributors, and winter was the worst season, followed by autumn and summer.

X. Han et al. (2014) pointed out that the haze formation mechanism in winter in Beijing was different from that in summer and mass concentrations of $\mathrm{PM}_{2.5}$ in winter were relatively higher and the compositions were different than in summer. The extreme winter haze in the NCP has attracted enormous scientific interests. It has been found that stagnant meteorological conditions (weak surface wind speed and low Planetary Boundary Layer (PBL) height) and secondary aerosol formation are the main causes of winter haze formation (S. Han et al., 2014; He et al., 2014b; K. Huang et al., 2014; Sun et al., 2014; Wang et al., 2014a; Zhao et al., 2013; B. Zheng et al., 2015; G. J. Zheng et al., 2015). Other causes proposed include high local emissions (He et al., 2014b; G. J. Zheng et al., 2015), enhanced coal com- 

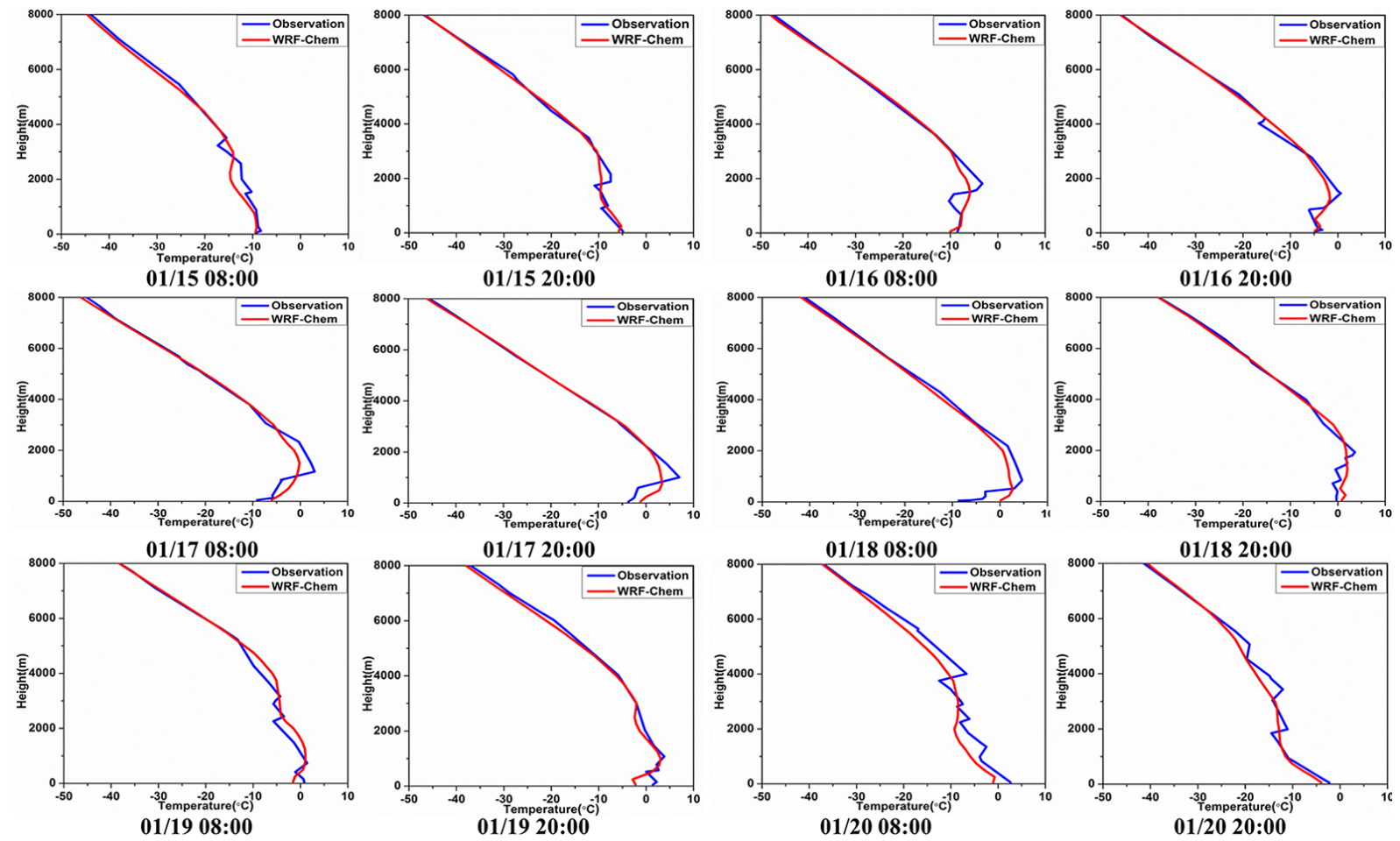

Figure 2. Simulated and observed vertical temperature profiles at 08:00 and 20:00 (China Standard Time, CST) from 15 to 20 January.

bustion in winter (K. Huang et al., 2014; Sun et al., 2014), heterogeneous chemistry (He et al., 2014a; X. Huang et al., 2014; Quan et al., 2014; Wang et al., 2014a, b; B. Zheng et al., 2015; G. J. Zheng et al., 2015) and regional transport (Tao et al., 2014; Sun et al., 2014; L. T. Wang et al., 2014; Z. Wang et al., 2014; G. J. Zheng et al., 2015). It was also pointed out that fog processing (K. Huang et al., 2014), aerosol-radiation interactions (J. Wang et al., 2014; Z. Wang et al., 2014; B. Zhang et al., 2015) and nucleation events (Guo et al., 2014) may play important roles in winter haze formation.

The complex haze formation mechanisms need further studies. Li et al. (2015) emphasized that regional transport of $\mathrm{PM}_{2.5}$ is a major cause of severe haze in Beijing, but $\mathrm{R}$. Zhang et al. (2015) pointed out that the evidence provided by $\mathrm{Li}$ et al. (2015) is insufficient and regional transport should be evaluated using chemical transport models. Furthermore, the contribution of aerosol feedbacks to $\mathrm{PM}_{2.5}$ levels remains unquantified. Therefore, the roles of regional transport and aerosol-radiation interactions in haze events need to be better understood. In this study, the online coupled model WRFChem, which is capable of simulating aerosols' effects on meteorology and climate, is used to reproduce the severe haze event that happened in the NCP from 16 to 19 January 2010. During this haze event, the highest hourly $\mathrm{PM}_{2.5}$ concentration reached 445.6 and $318.1 \mu \mathrm{g} \mathrm{m}^{-3}$ in Beijing and Tianjin and the areas with low visibility covered most eastern China regions (Zhao et al., 2013). In this study, we ad- dress the following important questions: (1) what is the performance of the model configurations in representing the meteorological variables, and the physical and chemical characteristics of the aerosols during the selected study period; (2) how does the haze build up and dissipate; (3) how do the chemical species of $\mathrm{PM}_{2.5}$ change during haze period; (4) does regional transport play an import role in the 2010 haze event in Beijing; (5) what is the contribution of aerosol feedback mechanisms to $\mathrm{PM}_{2.5}$ levels during the haze event; and (6) what is the role of BC absorption in the feedback mechanism? In Sect. 2, we describe the model we use and model configuration, including emissions and used parameterization schemes. In Sect. 3, surface meteorological, chemical observations, atmospheric sounding products, as well as remote-sensing products are used to evaluate the model performance. In Sect. 4, questions from (2) to (6) are answered in detail. Conclusions are provided in Sect. 5.

\section{Model description and configuration}

The WRF-Chem model version 3.5.1 was employed to simulate the 2010 haze event in the NCP region and aerosolradiation interactions were included (Chapman et al., 2009; Fast et al., 2006). Domain settings are the same as those of Jing-Jin-Ji modeled area of Yu et al. (2012). Three domains with two-way nesting were used and grid resolutions were $81 \mathrm{~km} \times 81 \mathrm{~km}$ (domain 1), $27 \mathrm{~km} \times 27 \mathrm{~km}$ (domain 2) and $9 \mathrm{~km} \times 9 \mathrm{~km}$ (domain 3; see Fig. S1 in the Supplement). 

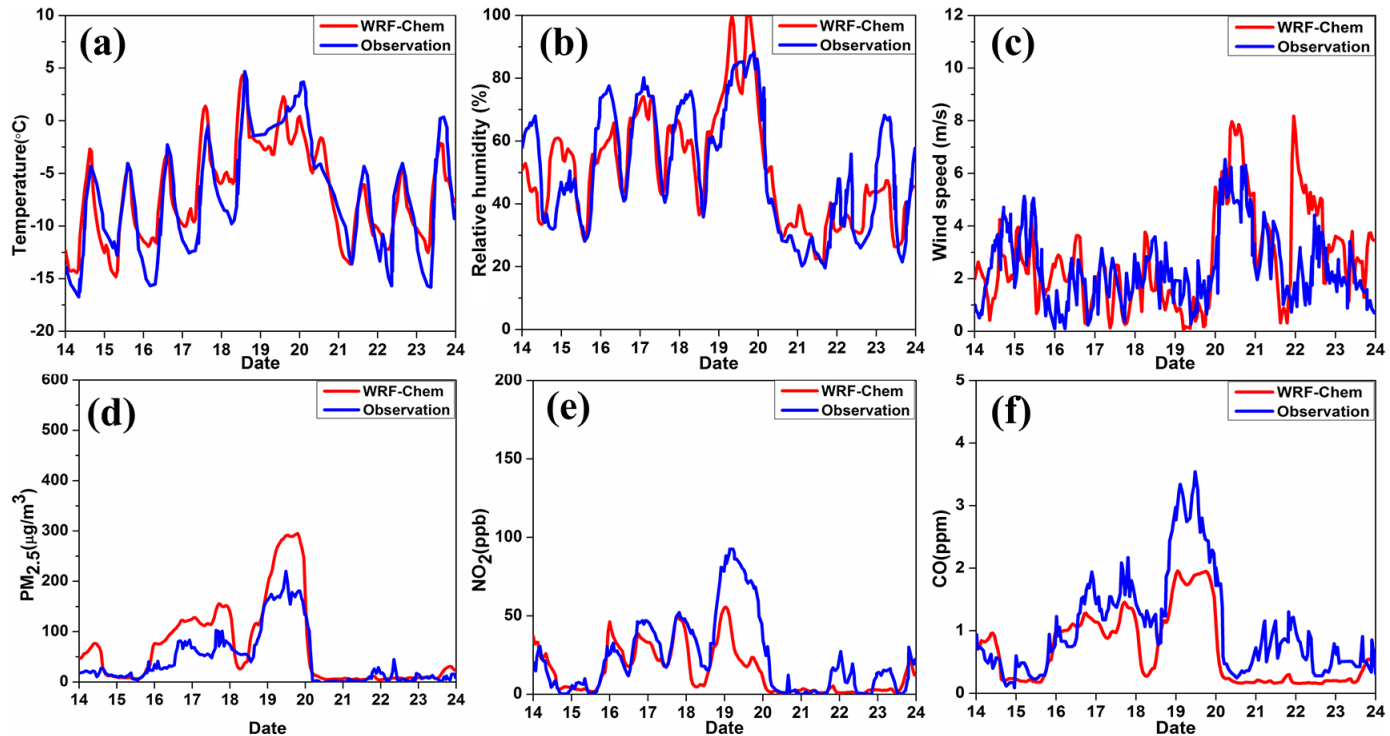

Figure 3. Simulated and observed hourly temperature, $\mathrm{RH}$, wind speed, $\mathrm{PM}_{2.5}, \mathrm{NO}_{2}$ and $\mathrm{CO}$ in the Shangdianzi (SDZ) station.
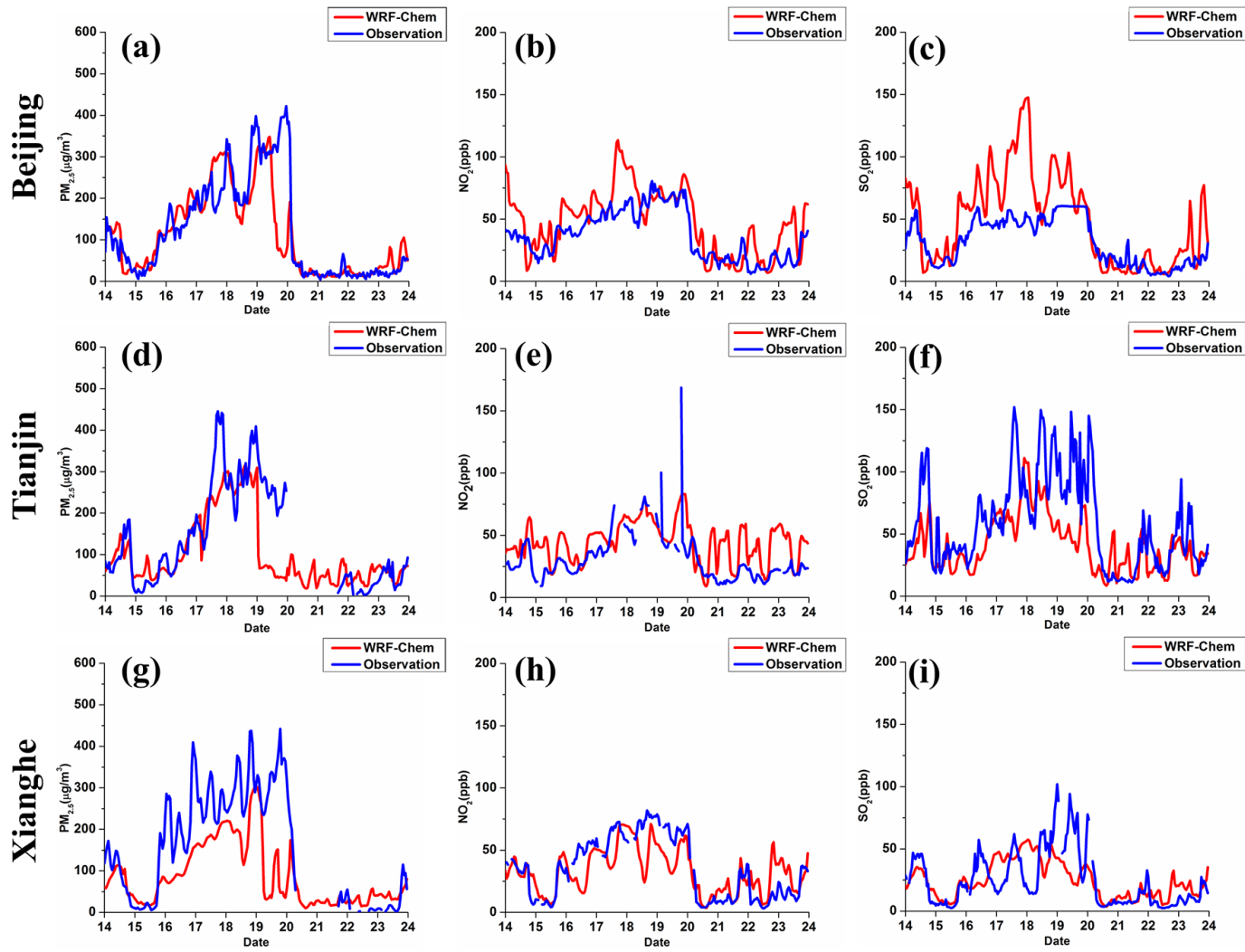

Figure 4. Temporal variations of the simulated and observed $\mathrm{PM}_{2.5}, \mathrm{NO}_{2}$ and $\mathrm{SO}_{2}$ at Beijing (a-c), Tianjin (d-f) and Xianghe (g-i) stations.

The number of vertical grids used was 27 and the number of horizontal grids was $81 \times 57,49 \times 49$, and $55 \times 55$, respectively. The first domain covers most areas of the East Asia region, including China, Korea, Japan and Mongolia. Beijing was set to be the center of the innermost nested do- main. The chemical and aerosol mechanism used was gasphase chemical mechanism CBMZ (Zaveri and Peters, 1999) coupled with the 8-bin sectional MOSAIC model with aqueous chemistry (Zaveri et al., 2008). MOSAIC treats all the important aerosol species, including sulfate, nitrate, chlo- 
Table 1. Observation data and variables used in this study.

\begin{tabular}{|c|c|c|c|c|}
\hline Data sets ${ }^{\mathrm{a}}$ & Variables ${ }^{b}$ & $\begin{array}{l}\text { Data } \\
\text { frequency }\end{array}$ & $\begin{array}{r}\text { Number of } \\
\text { sites used }\end{array}$ & Data sources \\
\hline CMDSSS & T2, RH2, WS10 & Daily & 4 & http://cdc.cma.gov.cn/home.do \\
\hline Atmospheric Sounding & $\mathrm{T}, \mathrm{RH}$ & $12 \mathrm{~h}$ & 1 & http://weather.uwyo.edu/upperair/sounding.html \\
\hline CARE-China & $\mathrm{PM}_{2.5}, \mathrm{NO}_{2}, \mathrm{SO}_{2}$ & Hourly & 3 & \\
\hline CSHNET & $\mathrm{AOD}$ & Hourly & 4 & \\
\hline SDZ & $\mathrm{T} 1.5, \mathrm{RH} 1.5, \mathrm{WS} 10, \mathrm{PM}_{2.5}, \mathrm{NO}_{2}, \mathrm{CO}$ & Hourly & 1 & Zhao et al. (2013) \\
\hline CALIPSO & $\mathrm{AOD}$ & N/A & N/A & http://www-calipso.larc.nasa.gov/ \\
\hline MODIS & AOD & Daily & N/A & http://ladsweb.nascom.nasa.gov/data/search.html \\
\hline
\end{tabular}
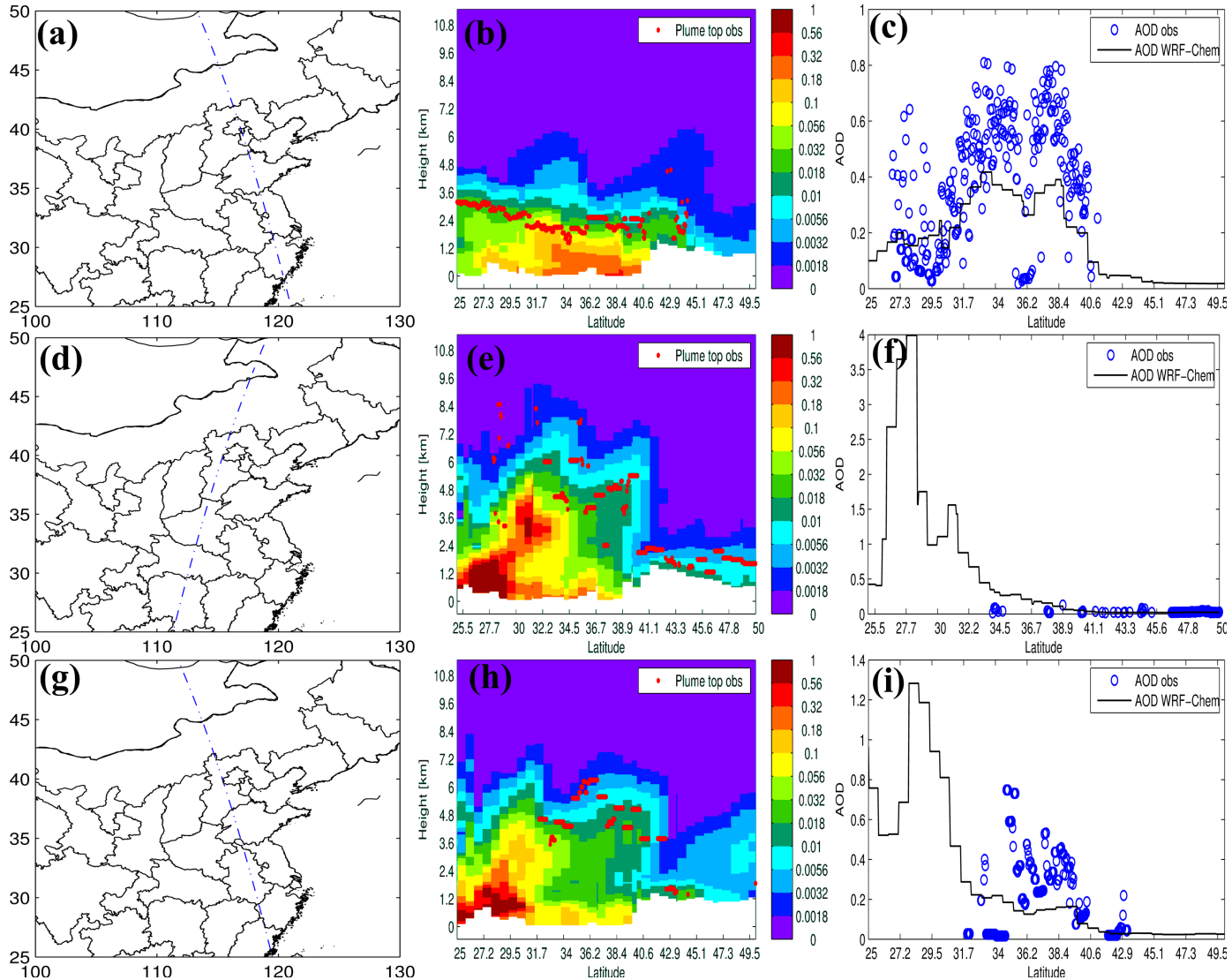

Figure 5. Routes of CALIPSO satellite, simulated extinction coefficient and observed plume top, and simulated AOD and CALIPSO retrieved AOD at $532 \mathrm{~nm}$ at three moments: 14 January 12:00 (CST, a-c), 21 January 02:00 (CST, d-f), and 21 January 12:00 (CST, g-i).

ride, ammonium, sodium, BC, primary organic mass, liquid water and other inorganic mass (Zaveri et al., 2008). Some of the physics configuration options include Lin cloudmicrophysics (Lin et al., 1983), RRTM long wave radiation (Mlawer et al., 1997), Goddard short wave radiation (Chou et al., 1998), Noah land surface model, and the Yonsei University planetary boundary layer parameterization (Hong et al., 2006).
Emissions are key factors in the accuracy of air quality modeling results. The monthly 2010 Multi-resolution Emission Inventory for China (MEIC; http://www.meicmodel. org/) was used as the anthropogenic emissions. This inventory includes emissions of sulfur dioxide $\left(\mathrm{SO}_{2}\right)$, nitrogen oxides $\left(\mathrm{NO}_{x}\right)$, carbon monoxide $(\mathrm{CO})$, non-methane volatile organic compounds (NMVOC), $\mathrm{NH}_{3}, \mathrm{BC}$, organic carbon (OC), $\mathrm{PM}_{2.5}, \mathrm{PM}_{10}$, and carbon dioxide $\left(\mathrm{CO}_{2}\right)$ by several sectors (power generation, industry, residential, transporta- 


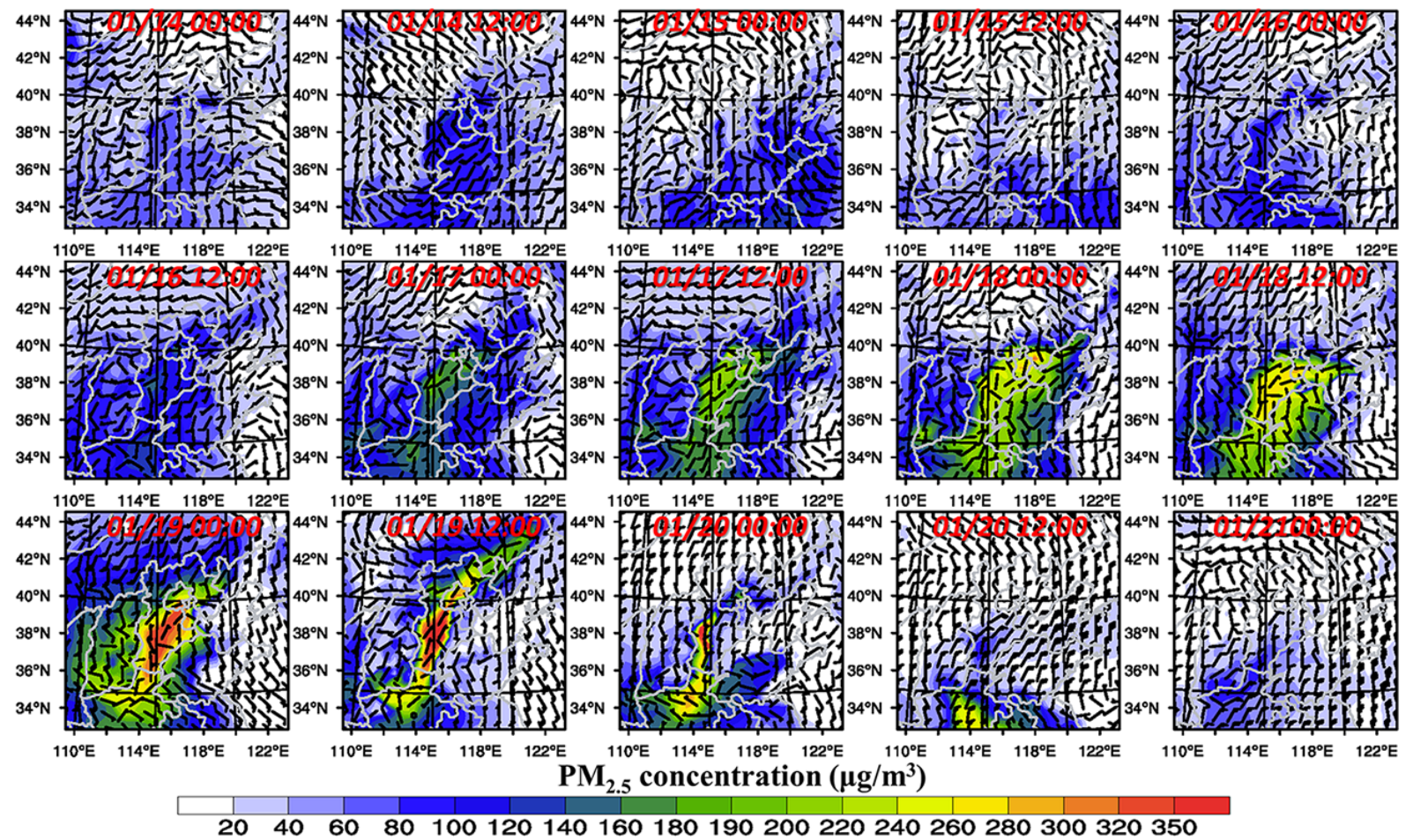

Figure 6. $\mathrm{PM}_{2.5}$ concentration from 14 January 00:00 to 21 January 00:00, plotted every $12 \mathrm{~h}$.

tion, etc.). Biogenic emissions were calculated on an online way by the MEGAN model (Guenther et al., 2006). Meteorological initial and boundary conditions were obtained from the National Centers for Environmental Prediction (NCEP) Final Analysis (FNL) data set. Chemical initial and boundary conditions were taken from MOZART-4 forecasts (Emmons et al., 2010). The period from 11 to 24 January 2010 was chosen as the modeling period, covering the $2010 \mathrm{NCP}$ haze period (from 16 to 19 January 2010). To overcome the impacts of initial conditions, 3 days were simulated and considered as spin-up time.

\section{Model evaluation}

\subsection{Observation data sets and evaluation metrics}

Model evaluation was conducted in terms of both temporal variation and spatial distribution. Table 1 gives a summary of the observation data and variables used in the model evaluation. The meteorological variables, including $2 \mathrm{~m}$ temperature (T2), $2 \mathrm{~m}$ relative humidity (RH2) and $10 \mathrm{~m}$ wind speed (WS10), at four stations (Beijing, Tianjin, Baoding and Chengde) were used. Surface concentrations of $\mathrm{PM}_{2.5}, \mathrm{NO}_{2}$, $\mathrm{SO}_{2}$ at three sites (Beijing, Tianjin and Xianghe, shown in Fig. S1), and Aerosol Optical Depth (AOD) at four sites (Beijing city, Beijing forest, Baoding city, Cangzhou city) were also used in the evaluation against measurements. $\mathrm{PM}_{2.5}$ and AOD are typical variables to represent severity of haze pollu- tion. To evaluate how model performs in simulating horizontal and vertical distributions of meteorological and chemical variables, soundings of temperature and $\mathrm{RH}$ at Beijing, and AODs derived from CALIPSO were used in this study. The statistical metrics calculated include correlation coefficient $R$, mean bias (MB), mean error (ME), the root mean square error (RMSE), the normalized mean bias (NMB), the normalized mean error (NME), the mean fractional bias (MFB) and the mean fractional error (MFE). The definitions of these metrics can be found in Morris et al. (2005) and Willmott and Matsuura (2005).

\subsection{Meteorology simulations}

Figure 1 shows the temporal variations of simulated and observed $24 \mathrm{~h}$ average temperature (a-d), relative humidity (e-h) and wind speed (i-l) at Beijing, Tianjin, Baoding and Chengde stations. These observations were collected from the China Meteorological Data Sharing Service System (CMDSSS) data set. From normal days to haze days (gray shaded), temperature and relative humidity increased and wind speeds decreased. Generally, the variations of surface temperature, RH and wind speeds are captured by model, although overestimations of wind speed occur at the Chengde station throughout the whole period. Model mean, observation mean, MB, ME and RMSE were calculated and summarized in Table 2. The MB and RMSE for surface temperature vary from -2.0 to $2.0 \mathrm{~K}$ and from 1.5 to $3.2 \mathrm{~K}$, respectively. 
Table 2. Performance statistics for meteorological variables.

\begin{tabular}{|c|c|c|c|c|c|c|c|c|c|c|c|c|c|c|c|c|c|c|c|c|}
\hline \multirow[b]{2}{*}{ Variables } & \multicolumn{5}{|c|}{ Beijing } & \multicolumn{5}{|c|}{ Tianjin } & \multicolumn{5}{|c|}{ Baoding } & \multicolumn{5}{|c|}{ Chengde } \\
\hline & Obs. & Mod. & MB & ME & RMSE & Obs. & Mod. & MB & ME & RMSE & Obs. & Mod. & MB & ME & RMSE & Obs. & Mod. & MB & ME & RMSE \\
\hline $\mathrm{T} 2(\mathrm{~K})$ & 269.5 & 267.6 & -1.9 & 2.0 & 2.5 & 269.3 & 268.1 & -1.1 & 1.2 & 1.5 & 270.4 & 268.5 & -2.0 & 2.0 & 2.3 & 262.5 & 264.5 & 2.0 & 2.4 & 3.2 \\
\hline RH2 (\%) & 46.9 & 53.4 & 6.6 & 7.2 & 11.1 & 61.5 & 58.4 & -3.1 & 5.9 & 6.4 & 44.4 & 52.5 & 8.1 & 8.1 & 10.4 & 59.4 & 55.0 & -4.4 & 8.0 & 8.8 \\
\hline $\mathrm{WS} 10\left(\mathrm{~m} \mathrm{~s}^{-1}\right)$ & 2.1 & 3.4 & 1.3 & 1.3 & 1.6 & 2.8 & 3.2 & 0.4 & 1.0 & 1.1 & 1.4 & 2.8 & 1.4 & 1.4 & 2.1 & 1.4 & 2.9 & 1.5 & 1.5 & 1.8 \\
\hline
\end{tabular}
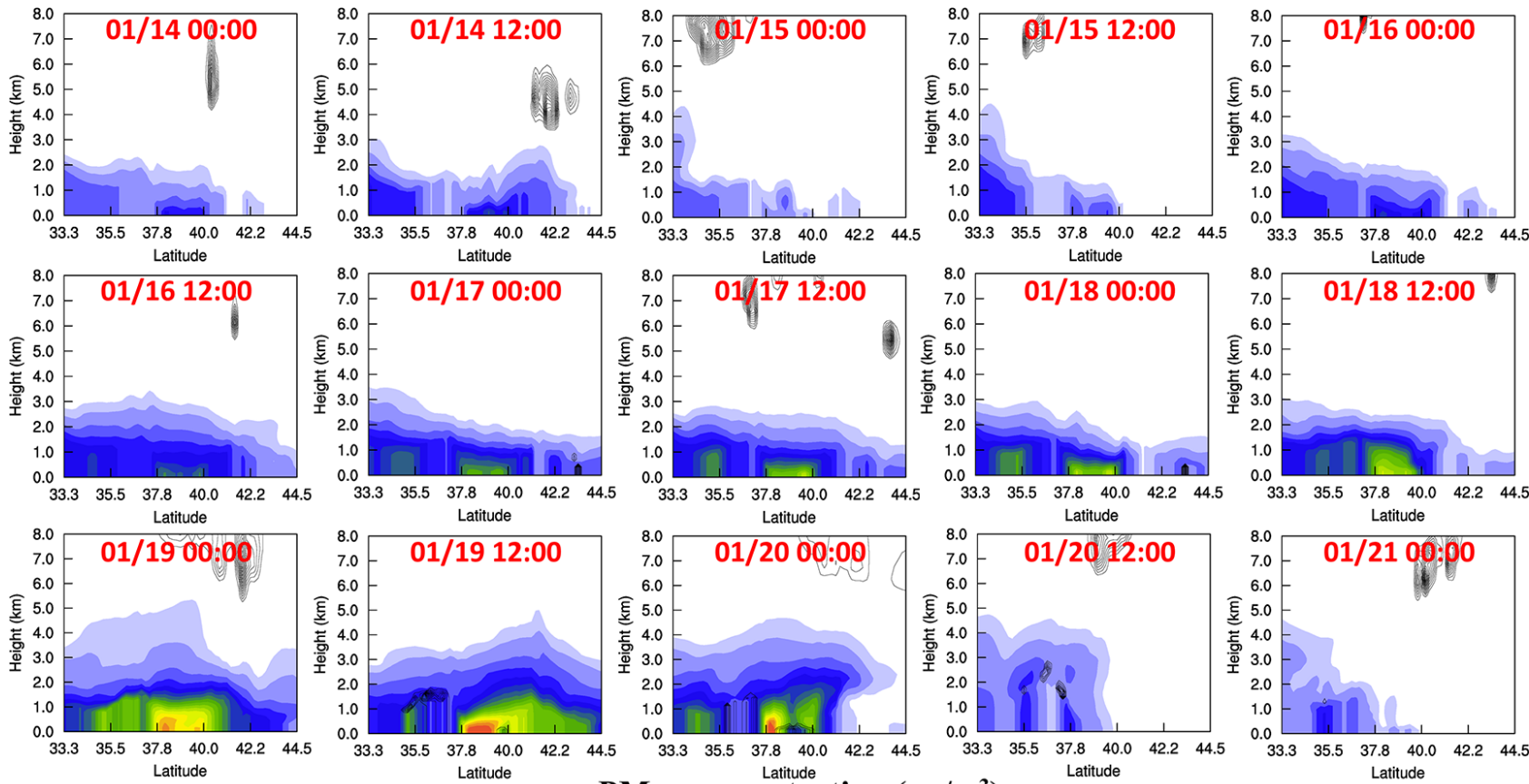

$\mathrm{PM}_{25}$ concentration $\left(\mu \mathrm{g} / \mathrm{m}^{3}\right)$

$20 \quad 60 \quad 100 \quad 140 \quad 180 \quad 220 \quad 260 \quad 300 \quad 350$

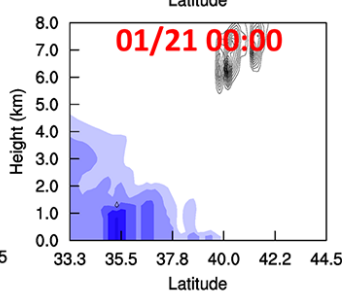

Figure 7. Cross section plots of $\mathrm{PM}_{2.5}$ concentration and clouds from 14 January 00:00 to 21 January 00:00 every $12 \mathrm{~h}$.

The model underestimates temperature at Beijing, Tianjin and Baoding stations, and overestimates temperature at the Chengde station. RH agrees well with observations, with MB varying from -4.4 to $8.1 \%$ and RMSE varying from 6.4 to $11.1 \%$. The magnitudes of MB and RMSE are comparable with those of Wang et al. (2014b). The model shows good performance in simulating wind speed, with RMSE ranging from 1.1 to $1.6 \mathrm{~m} \mathrm{~s}^{-1}$ at Beijing, Tianjin and Baoding stations, below the level of "good" model performance criteria for wind speed prediction proposed by Emery et al. (2001). Wind speeds at the Chengde station were overestimated, with RMSE larger than the proposed criteria $\left(2 \mathrm{~m} \mathrm{~s}^{-1}\right)$.

Figure 2 compares simulated and observed vertical temperature profiles at 08:00 and 20:00 (CST) from 15 to 20 January at Beijing city. These atmospheric sounding data are from the NCAR Earth observing laboratory atmospheric sounding data set. The model captures the vertical profiles of temperature well. Obvious strong temperature inversions existed during the haze period (from 16 January 08:00 CST to 19 January 20:00 CST) and the lapse rate during this period was about $5-15^{\circ} \mathrm{C} \mathrm{km}^{-1}$, indicating unfavorable conditions for diffusion of pollutants. The model captures the general vertical profiles of $\mathrm{RH}$, although the performance is not as good as for temperature (see Fig. S2).

\subsection{Chemical simulations}

Figure $3 \mathrm{~d}-\mathrm{f}$ shows variations of simulated and observed hourly $\mathrm{PM}_{2.5}, \mathrm{NO}_{2}$ and $\mathrm{CO}$ at the SDZ station. The haze event started from 16 January with rapid increase of $\mathrm{PM}_{2.5}$, $\mathrm{NO}_{2}$, and $\mathrm{CO}$ concentrations and ended on 20 January. The relationships between meteorological condition and pollution levels are clearly shown. Both the observation and the model show that temperature and relative humidity increase, wind speeds are low, and pollution levels build up (Fig. 3). The magnitudes and trends over time of the simulated $\mathrm{PM}_{2.5}$, $\mathrm{NO}_{2}$ and $\mathrm{CO}$ are generally consistent with measurements, although overestimation of $\mathrm{PM}_{2.5}$ and underestimations of $\mathrm{NO}_{2}$ and $\mathrm{CO}$ exist during the haze days. Figure 4 shows the temporal variations of the simulated and observed $\mathrm{PM}_{2.5}$, $\mathrm{NO}_{2}$ and $\mathrm{SO}_{2}$ at Beijing $(\mathrm{a}-\mathrm{c})$, Tianjin (d-f) and Xianghe (g-i) stations. The observations and the model predictions 
Table 3. Performance statistics of $\mathrm{PM}_{2.5}$.

\begin{tabular}{lrrcrrrrrr}
\hline & $\begin{array}{r}\text { Obs. } \\
\left(\mu \mathrm{g} \mathrm{m}^{-3}\right)\end{array}$ & $\begin{array}{r}\text { Model } \\
\left(\mu \mathrm{g} \mathrm{m}^{-3}\right)\end{array}$ & $R$ & $\begin{array}{r}\text { MB } \\
\left(\mu \mathrm{g} \mathrm{m}^{-3}\right)\end{array}$ & $\begin{array}{r}\text { ME } \\
\left(\mu \mathrm{g} \mathrm{m}^{-3}\right)\end{array}$ & $\begin{array}{r}\text { NMB } \\
(\%)\end{array}$ & $\begin{array}{r}\text { NME } \\
(\%)\end{array}$ & $\begin{array}{r}\text { MFB } \\
(\%)\end{array}$ & $\begin{array}{r}\text { MFE } \\
(\%)\end{array}$ \\
\hline Beijing & 111.7 & 122.1 & 0.77 & -10.4 & 30.4 & -8.5 & 24.9 & 0.4 & 26.3 \\
Tianjin & 103.3 & 141.2 & 0.75 & -37.9 & 56.1 & -26.9 & 39.7 & -7.8 & 49.6 \\
Xianghe & 93.0 & 152.6 & 0.69 & -59.7 & 68.0 & -39.1 & 44.5 & -21.8 & 50.7 \\
\hline
\end{tabular}

show that the buildups of pollution during the haze event were similar at these three sites, occurring over a large geographical region at the same time. $\mathrm{SO}_{2}$ was overestimated in Beijing, but other simulations agree well with observations, especially for $\mathrm{PM}_{2.5}$. Observation mean, model mean, $\mathrm{MB}$, ME, NMB, NME, MFB, and MFE were calculated for $24 \mathrm{~h}$ average simulated and observed $\mathrm{PM}_{2.5}$ at these three stations and summarized in Table 3. As shown in Table 3, the model underestimates $\mathrm{PM}_{2.5}$ concentrations at all stations. NMBs for $\mathrm{PM}_{2.5}$ are $-8.5,-26.9$ and $-39.1 \%$ at Beijing, Tianjin and Xianghe, respectively. MFBs at these three stations range from -21.8 to $0.4 \%$ and MFEs range from 26.3 to $50.7 \%$. They are all within the criteria proposed by Boylan and Russel (2006) that model performance is "satisfactory" when MFB is within $\pm 60 \%$ and MFE is below $75 \%$. Although the model performance for $\mathrm{PM}_{2.5}$ is satisfactory, biases still exist, especially during severe haze days. Reasons for the biases might be errors in meteorological variables, large uncertainties of emission inventory, effects of horizontal and vertical resolutions, and incomplete treatments of atmospheric chemistry. Many atmospheric chemistry reactions have been and are being proposed for PM formation in winter haze. For example, He et al. (2014a) proposed that mineral dust and $\mathrm{NO}_{x}$ could promote the formation of sulfate in heavy pollution days. The sensitivity of the simulations to some of these factors will be discussed in future studies.

\subsection{Simulations of optical properties}

In WRF-Chem, aerosol optical properties are calculated at four specific wavelengths, $300,400,600$, and $1000 \mathrm{~nm}$, while AOD observations from CSHNET, CALIPSO are not at these four wavelengths. To evaluate model performance of simulating AOD, we derived AOD at observation wavelengths based on Angstrom exponent relation (Schuster et al., 2006). In severe haze days, AOD could not be retrieved, so the observed AOD data in some days are missing. Model agrees very well with the CSHNET AOD observations at all four stations (Fig. S3).

CALIPSO retrievals provide vertical curtains of aerosol and clouds. Figure 5 shows paths of the CALIPSO satellite, simulated extinction coefficient and observed plume top, and simulated AOD and CALIPSO retrieved AOD at 532nm at three moments: 14 January 12:00 CST (a-c), 21 January 02:00 CST (d-f), and 21 January 12:00 CST (g-i), respec-

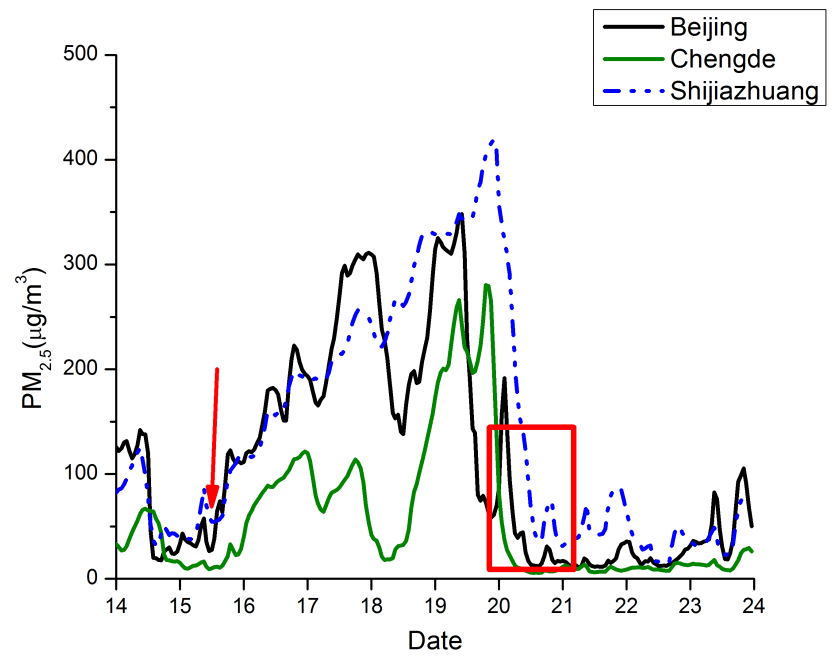

Figure 8. Temporal variations of simulated $\mathrm{PM}_{2.5}$ at Shijiazhuang, Beijing and Chengde.

tively. There were no retrievals in the NCP during haze days. Figure 5a, $\mathrm{d}$ and $\mathrm{g}$ show that the CALIPSO satellite passed over the NCP region at these three moments. Simulated extinction coefficient matches observed plume top (Fig. 5b, e and $\mathrm{h}$ ), indicating that the model captures the vertical distributions of aerosols. The model also has good performance in simulating AOD at $532 \mathrm{~nm}$, although underestimations happen around latitude $36^{\circ} \mathrm{N}$ (Fig. 5c, f and i).

The model is shown to be capable of simulating the major meteorological and chemical evolution of this haze event. As spatial and vertical profiles of the haze period are incomplete or missing in the satellite retrievals and ground stations only provide point estimates, we can use the model to understand the haze spatial, vertical and temporal evolution, as discussed in the following sections.

\section{Results and discussions}

\subsection{Meteorological conditions and evolution of air pollutants}

The evolution of the spatial distributions of the haze event is shown in Fig. 6, where the horizontal distributions of $\mathrm{PM}_{2.5}$ and wind vectors are plotted every $12 \mathrm{~h}$ from $14 \mathrm{Jan}-$ uary 00:00 CST to 21 January 00:00 CST. In the second plot 


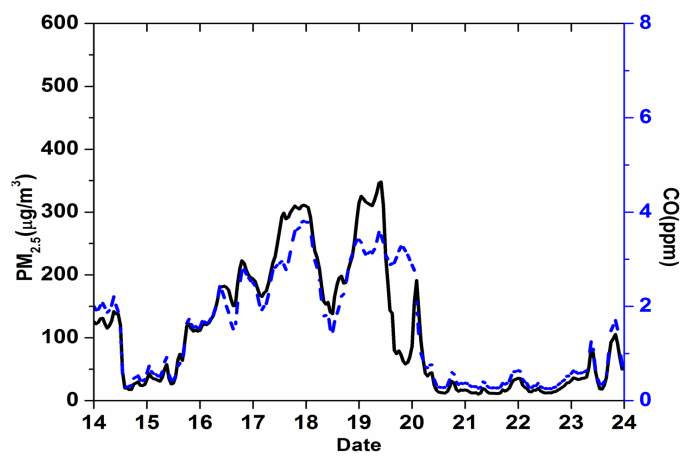

(a)

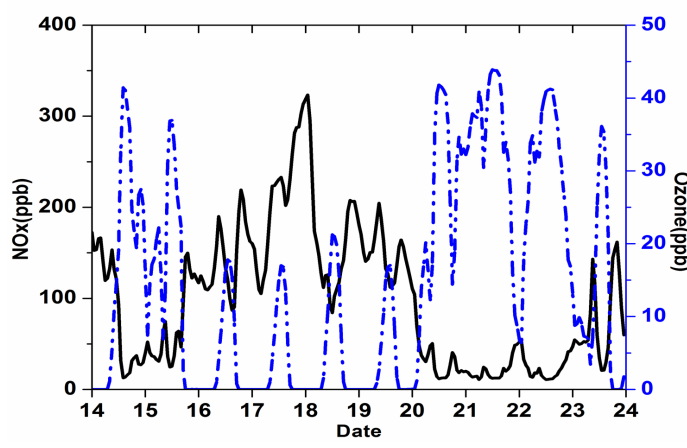

(c)

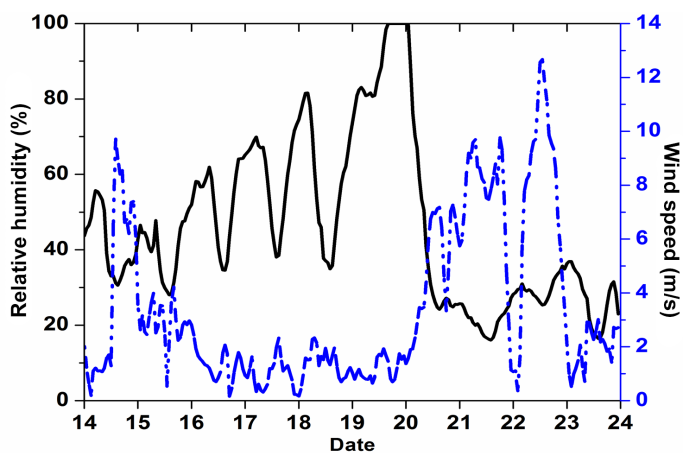

(b)

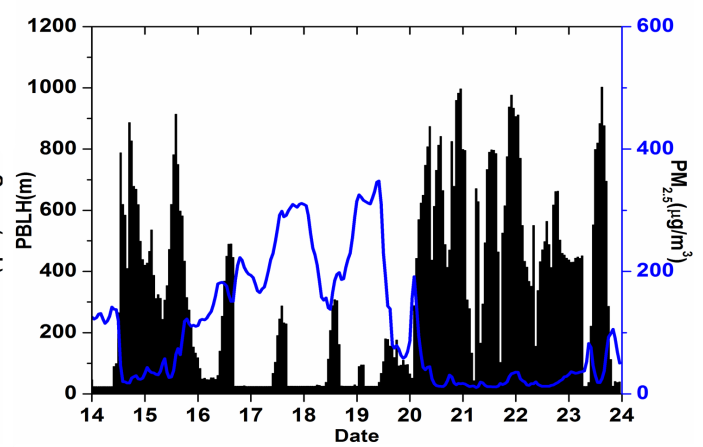

(d)

Figure 9. Simulated temporal variations of meteorological and chemical variables in Beijing.

(14 January 12:00 CST), air flows converged at the NCP surface areas, resulting in a small increase of $\mathrm{PM}_{2.5}$ concentration. From 14 January 00:00 CST to 16 January 00:00 CST, $\mathrm{PM}_{2.5}$ concentration over the NCP was generally below $120 \mu \mathrm{g} \mathrm{m}^{-3}$. From 16 to 18 January Beijing and surrounding areas were controlled by a weak high pressure system (Zhao et al., 2013). During this period, large amounts of emissions in the NCP accumulated and the persistent southerly winds brought some air pollutants northward to Beijing and southern Hebei areas. The weak high pressure system was replaced by a low pressure system that lasted until 20 January and this weather condition was not conductive for dispersion of air pollutants (Zhao et al., 2013). On 19 January the NCP haze was in the worst state, with $\mathrm{PM}_{2.5}$ concentrations above $350 \mu \mathrm{g} \mathrm{m}^{-3}$ in south NCP. From 20 January strong northerly winds dispersed the accumulated air pollutants and the haze ended.

To illustrate the vertical structure of the haze, vertical cross sections of $\mathrm{PM}_{2.5}$ concentration and clouds are presented in Fig. 7. The cross section diagonally cuts the region with the lower left corner of $34^{\circ} \mathrm{N}, 110^{\circ} \mathrm{E}$ to the upper corner at $44^{\circ} \mathrm{N}, 122^{\circ} \mathrm{E}$ (see Fig. S4). There were two highly polluted points (around latitudes 35 and 39) and they started merging as one from 18 January 12:00 (Fig. 7). At that time, southerly winds blew air pollutants northwards (Fig. 6) and the polluted region was expanded. On 19 January there were fog and/or clouds near the surface and the impacts of fog and/or clouds will be discussed in Sect. 4.2.

Further details of the evolution of the haze are shown in the temporal variations of $\mathrm{PM}_{2.5}$ concentrations in Shijiazhuang, Tianjin and Chengde (marked in Fig. S1) in Fig. 8. All three sites show similar temporal variations. Around noon of 15 January $\mathrm{PM}_{2.5}$ concentrations in Shijiazhuang, Chengde and Beijing increased at nearly the same time, labeled by red arrow in Fig. 8. Air pollutants started accumulating when the NCP was controlled by the weak and stable weather conditions. Compared to Shijiazhuang and Beijing, the capital city of Hebei province and the capital of China, $\mathrm{PM}_{2.5}$ concentrations in Chengde were lower (Fig. 8). It was estimated that there are more than 8100 coal-fired boilers and industrial kilns in Shijiazhuang city (Peng et al., 2002), resulting in high intensity of emissions in Shijiazhuang. On 20 January Chengde was the first to show a sharp decrease of $\mathrm{PM}_{2.5}$ concentrations, followed by Beijing and Shijiazhuang, corresponding to the northerly wind impacts discussed above.

To better understand the relationships between meteorological factors and pollution levels, time series of different pairs of variables are shown in Fig. 9. CO shows very high correlation with $\mathrm{PM}_{2.5}$ (Fig. 9a), which is consistent with the observation and modeling results in Santiago, Chile (Perez et al., 2004; Saide et al., 2011), and shows the large contribution of primary sources (including gaseous precursors) 


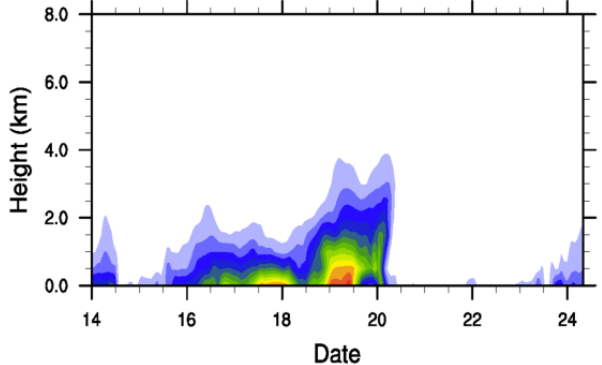

(a)

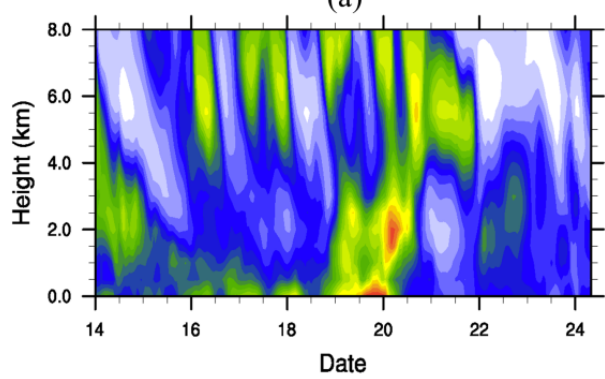

(c)

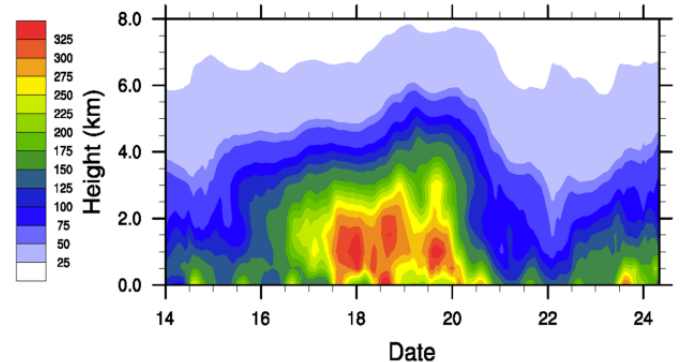

(b)

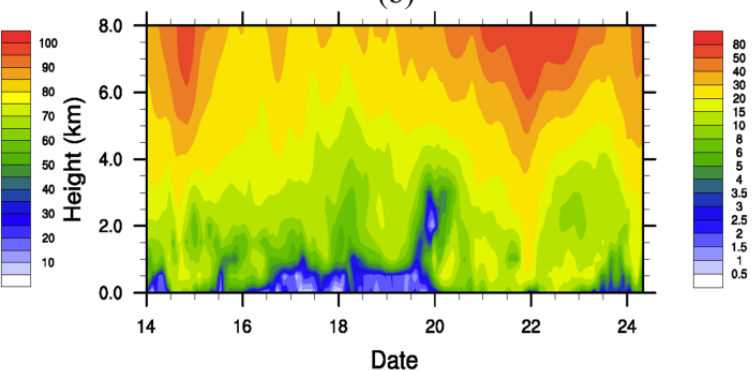

(d)

Figure 10. Temporal variations of vertical profiles of simulated (a) $\mathrm{PM}_{2.5}$ (unit: $\mu \mathrm{g} \mathrm{m}{ }^{-3}$, b) temperature (unit: ${ }^{\circ} \mathrm{C}, \mathbf{c}$ ) $\mathrm{RH}$ (unit: $\%$, d) wind speeds (unit: $\mathrm{m} \mathrm{s}^{-1}$ ) in Beijing.
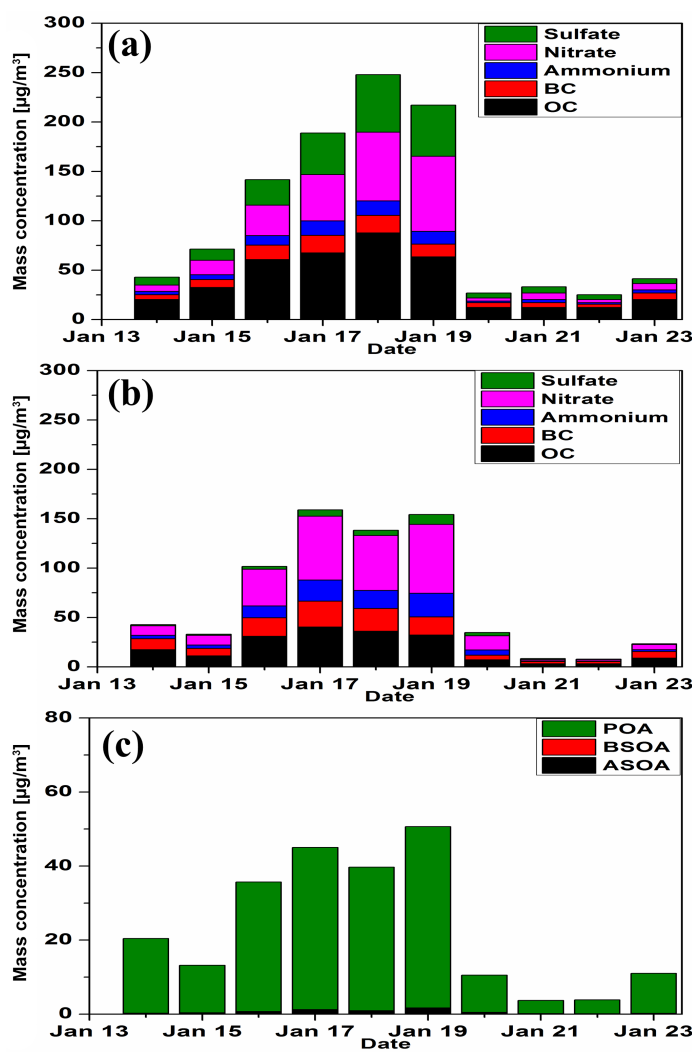

Figure 11. Observed (a) and simulated (b) chemical species of $\mathrm{PM}_{2.5}$ and simulated SOA (c) in the Beijing site. to $\mathrm{PM}_{2.5}$. Secondary aerosol formation also plays a role as $\mathrm{PM}_{2.5}$ peaks on the 19 th while $\mathrm{CO}$ peaks on the 18 th. $\mathrm{RH}$ and wind speed are two important factors affecting the concentrations of aerosols. $\mathrm{RH}$ has similar variations as $\mathrm{PM}_{2.5}$ concentration (shown in Figs. 9a and 5b). The NCP is close to the sea and under the slow southerly flows, temperature and $\mathrm{RH}$ increase along with $\mathrm{PM}_{2.5}$. During the haze event, RH values were generally above $40 \%$ and wind speeds were below $2 \mathrm{~m} \mathrm{~s}^{-1}$ (Fig. 9b). Low wind speed is unfavorable for the dilution of air pollutants and high $\mathrm{RH}$ would accelerate the formation of secondary species, such as sulfate and nitrate, to aggravate the pollution level (Sun et al., 2006). $\mathrm{NO}_{X}$ concentrations show similar variations as $\mathrm{PM}_{2.5}$, indicating the buildup of concentrations during the wind speed stagnation. Ozone shows lower concentrations during haze event (Fig. 9c) because high aerosol loadings produce low photochemical activity due to decrease in UV radiation. The concentrations have an inverse relationship with PBL Height (PBLH) as shown in Fig. 9d. Diurnal maximums of PBLHs were mostly below $400 \mathrm{~m}$ and PBL collapsed at night during the haze event, indicating aerosols were trapped near the surface. On 21 and 22 January PBLHs were between 800 and $1000 \mathrm{~m}$, which helped diffuse and dilute the air pollutants, resulting in a decrease in concentration. The relationships between these variables are further discussed with respect to the influences of aerosol feedback mechanism in Sect. 4.4.

Figure 10 shows the temporal variations of vertical profiles of simulated $\mathrm{PM}_{2.5}$ concentration (a), temperature (b), $\mathrm{RH}$ (c) and wind speeds (d) at the Beijing site. $\mathrm{PM}_{2.5}$ was accumulated below $500 \mathrm{~m}$ and concentrations reached peak val- 
Table 4. Primary aerosol, SIA and SOA $\left(\mu \mathrm{g} \mathrm{m}^{-3}\right)$ during haze days and non-haze days in Beijing.

\begin{tabular}{lrrr}
\hline & Primary & SIA & SOA \\
\hline Haze days & 56.4 & 81.9 & 1.1 \\
Non-haze days & 14.2 & 10.8 & 0.3 \\
Ratio & 4.0 & 7.6 & 3.7 \\
\hline
\end{tabular}
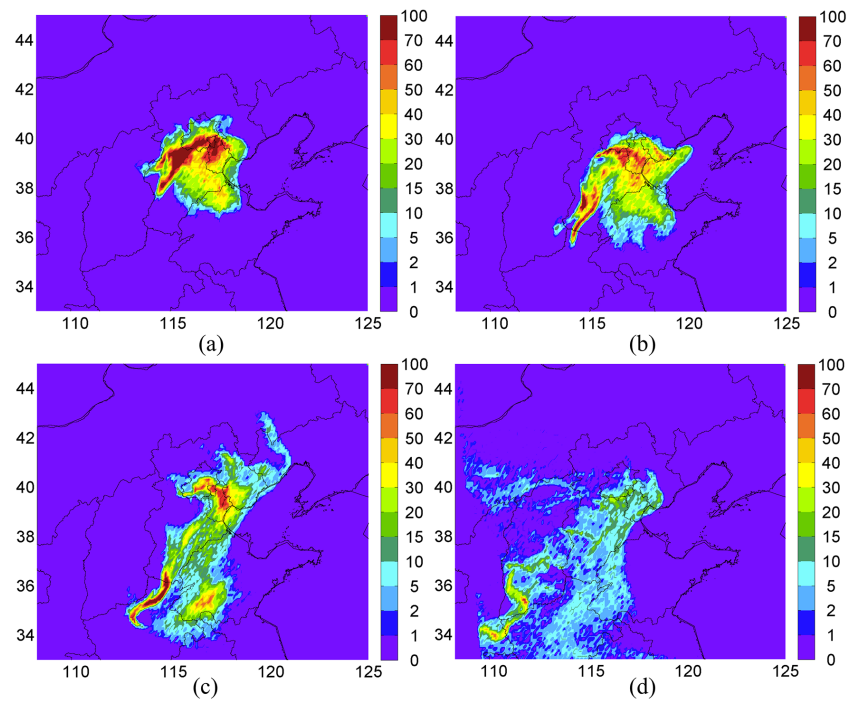

Figure 12. Backward dispersion of particles released on 19 January 00:00, plotted $6,12,24$, and $48 \mathrm{~h}$ before being released (unit: number/grid cell).

ues around 18 January 00:00 (Fig. 10a), when a strong temperature inversion happened over Beijing (Fig. 10b), which inhibited vertical atmospheric mixing. A strong temperature inversion also happened on 19 January (Fig. 10b). From 16 to 19 January RH was mostly higher than $50 \%$ and reached a peak on the night of 19 January (Fig. 10c). As a result, air pollutants released into the atmosphere were trapped in the moist atmosphere and accumulated as near surface horizontal winds were very weak (below $1.5 \mathrm{~m} \mathrm{~s}^{-1}$ ) during the haze period (Fig. 10d). As mentioned above, the high RH enhances the formation of secondary species, which will be discussed in the following section.

\subsection{Evolution of aerosol composition during haze}

As shown above, during haze events, aerosols build up due to low mixing heights and low wind speeds. An important question is what is the role of secondary aerosol formation during such events? Previous measurement studies have found that the increase of secondary inorganic pollutants could be considered as a common property of haze pollution in East China (Zhao et al., 2013). The observed and simulated chemical species of $\mathrm{PM}_{2.5}$ in Beijing are shown in Fig. 11a and b, respectively. Observed secondary inorganic aerosols (SIA;
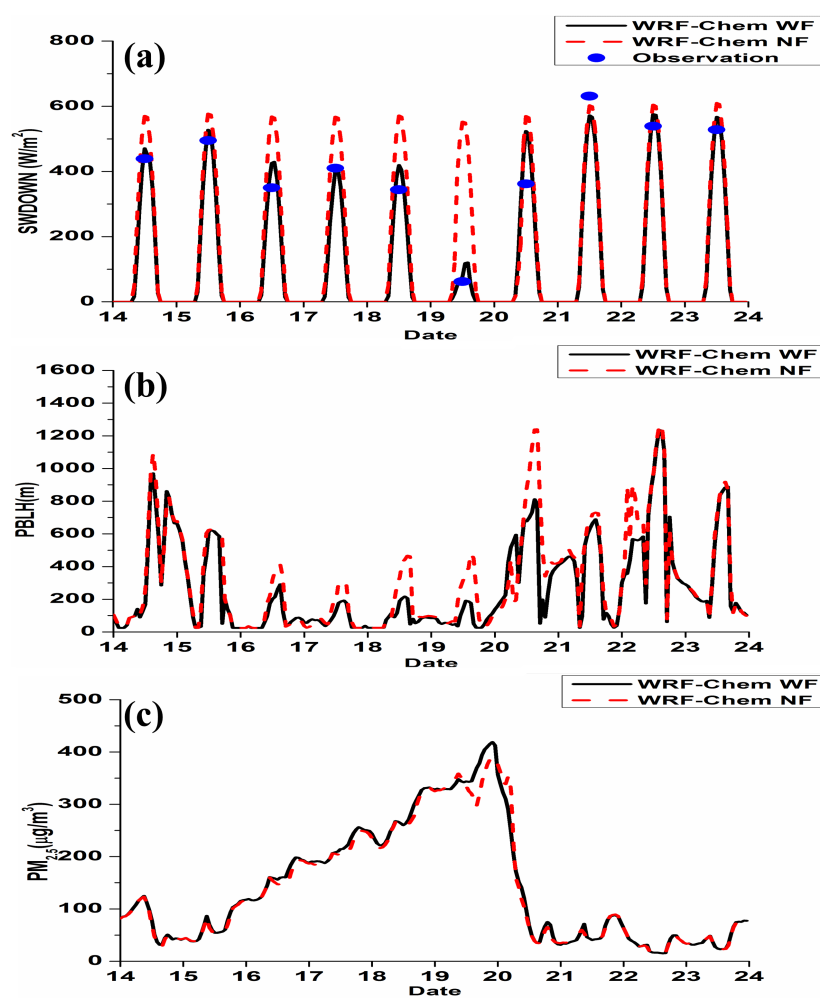

Figure 13. Observed daily maximum surface solar radiation and simulated surface shortwave radiation for the with feedback (WF) and without feedback (NF) scenarios in Beijing (a), simulated PBLH (b) in WF and NF scenarios at Shijiazhuang, and simulated $\mathrm{PM}_{2.5}$ concentration (c) in WF and NF scenarios at Shijiazhuang.

$\mathrm{NH}_{4}^{+}, \mathrm{SO}_{4}^{2-}, \mathrm{NO}^{3-}$ ) increased significantly during the haze episode and accounted for $37.7 \%$ of $\mathrm{PM}_{2.5}$ mass concentration (Zhao et al., 2013). Primary OC, BC, sulfate, nitrate and ammonium accounted for the major parts of the simulated $\mathrm{PM}_{2.5}$ during haze. Table 4 summarizes the mean concentrations of primary aerosols (primary OC and $\mathrm{BC}$ ) and SIA $\left(\mathrm{NH}_{4}^{+}, \mathrm{SO}_{4}^{2-}, \mathrm{NO}^{3-}\right)$ in non-haze days, and in the most serious haze day. The primary aerosols increased by a factor of 4.0 from non-haze days to haze days. The SIA also increased from non-haze days to haze days, which agrees with the observation (Tan et al., 2009; Zhao et al., 2013). The SIA increased by a factor of 7.6 from non-haze days to haze days. The increasing factors for observed primary aerosols and SIA are 2.9 and 6.9, which are close to those factors from simulations. However, the amounts of sulfate are underestimated by WRF-Chem, compared with the observation in Fig. 11a from Zhao et al. (2013). Tuccella et al. (2012) pointed out that the underestimation of simulated sulfate could be due to the underestimation of $\mathrm{SO}_{2}$ gas phase oxidation, errors in nighttime boundary layer height predicted by WRF-Chem, and/or the uncertainties in aqueous-phase chemistry. It could also be caused by the missing heterogeneous sulfate formation in current model (He et al., 2014a; Wang et al., 2014; B. Zheng 

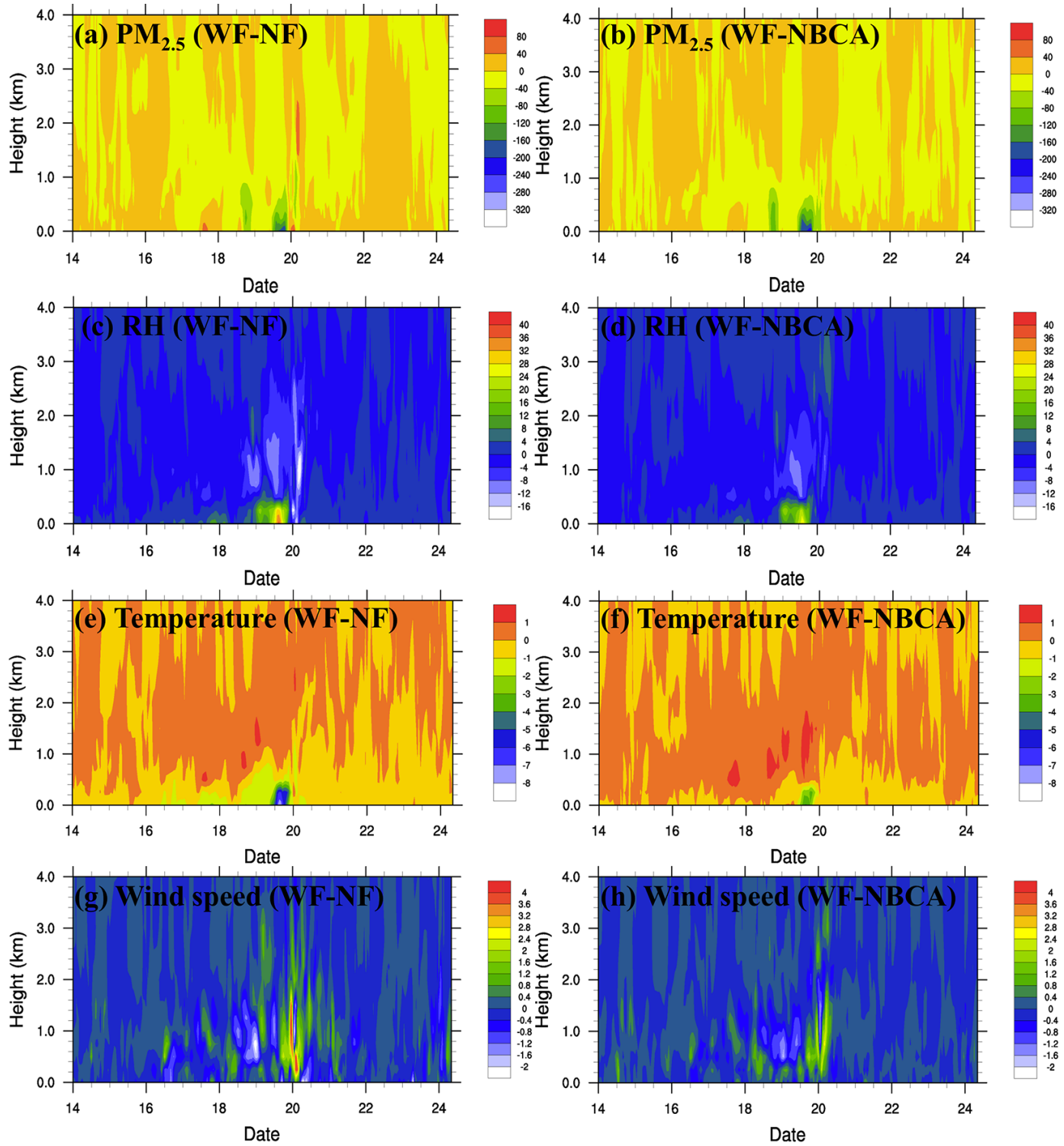

Figure 14. Temporal variations of vertical profiles of (a) $\mathrm{PM}_{2.5}$ (unit: $\mu \mathrm{g} \mathrm{m}{ }^{-3}$, c) $\mathrm{RH}$ (unit: \%, e) temperature (unit: ${ }^{\circ} \mathrm{C}$, g) wind speeds (unit: $\mathrm{m} \mathrm{s}^{-1}$ ) differences in Beijing between WF and NF scenarios; (b), (d), (f) and (h) are $\mathrm{PM}_{2.5}, \mathrm{RH}$, temperature and wind speeds differences in Beijing between WF and NBCA (BC absorptions are teased out) scenarios.

et al., 2015). As discussed earlier, the $\mathrm{SO}_{2}$ gas phase concentrations at this site were overestimated. Adding reaction pathways to produce sulfate aerosol would improve both the predictions of sulfate (increase) and $\mathrm{SO}_{2}$ (decrease; He et al., 2014a; Wang et al., 2014; B. Zheng et al., 2015).

We investigated the role of aqueous phase chemistry during the haze event. The aqueous phase pathway can reach a level of over $50 \mathrm{\mu g} \mathrm{m}^{-3}$ around the Beijing area, accounting for a significant part (about $14.3 \%$ ) of total $\mathrm{PM}_{2.5}$ concentration (see Fig. S5). As shown in Fig. 7, fog/clouds existed near the surface on 19 January and this corresponds to the $\mathrm{PM}_{2.5}$ difference on that day due to aqueous phase pathway. The sulfate production in aqueous phase may be higher than shown in this study after adding missing aqueous-phase reactions. The impacts of heterogeneous reactions on sulfate production will be investigated in future studies.

As shown in Figs. 1a and 7b, the model underestimates OC. To evaluate the formation of Secondary Organic Aerosol (SOA) during the haze event, the RADM2/MADESORGAM model was used. The CBMZ/MOSAIC version used is not capable of simulating SOA formation because CBMZ was hard-wired with a numerical solver in WRFChem and thus SOA condensable precursors could not be directly added into it (Zhang et al., 2012). RADM2 is an upgrade of RADM1 and it gives more realistic predictions of $\mathrm{H}_{2} \mathrm{O}_{2}$ (Stockwell et al., 1990), and Schell et al. (2001) incor- 
porated SOA into the Modal Aerosol Dynamics Model for Europe (MADE; Ackermann et al., 1998) by means of the Secondary Organic Aerosol Model (SORGAM). SORGAM treats anthropogenic and biogenic aerosol precursors separately and eight SOA compounds are considered, of which four are anthropogenic and the other four are biogenic (Schell et al., 2001). Predicted Anthropogenic SOA (ASOA), biogenic SOA (BSOA) and Primary Organic Aerosol (POA) in Beijing are shown in Fig. 11c. SOA indeed shows a marked increase from non-haze days to haze days, but the amount of SOA is very small compared with POA. The highest SOA concentrations in China are usually found in summer and in Central China (Jiang et al., 2012). In addition, almost all of the simulated SOA are ASOA. Jiang et al. (2012) also concluded that in winter, the fractions of ASOA are larger than $90 \%$ in north China. Biogenic emissions are usually controlled by solar radiation and temperature, and solar radiation is weaker and temperature is lower in winter compared with summer. Moreover, the high isoprene, API (apinene and other cyclic terpenes with one double bond) and LIM (limonene and other cyclic diene terpenes) emissions are located below $30^{\circ} \mathrm{N}$ and in Northeast China (Jiang et al., 2012), not in the NCP, so the SOA concentrations are not high in this winter haze event period in the NCP. As shown in Table 4, the mean SOA concentration in non-haze days is $0.15 \mu \mathrm{g} \mathrm{m}^{-3}$ and in the most serious haze day is $8.2 \mu \mathrm{g} \mathrm{m}^{-3}$. The factor increase of SOA from non-haze days to haze day is 8.2, which is lower than that of primary aerosols and much lower than that of SIA. The SOA formation in winter has not been well studied and it might be underestimated by the model as it could have missing pathways to SOA formation. Further work is needed to improve the underestimation of SOA formation in the winter.

\subsection{Impacts of surrounding areas on haze in Beijing}

Previous studies found that both local emissions and regional transport have significant contributions to the high fine particle levels in Beijing (Yang et al., 2011). A sensitivity simulation was conducted to quantify the contributions of surrounding areas to haze in Beijing, when Beijing local emissions were turned off. The ratio of $\mathrm{PM}_{2.5}$ in Beijing when Beijing emissions are turned off to $\mathrm{PM}_{2.5}$ in Beijing when Beijing emissions are on represents the non-local contributions. It can reach above $80 \%$ during haze (see Fig. S6) and the average contribution is about $65 \%$ from 16 to 19 January.

To figure out the dominant transport paths, FLEXPARTWRF (Stohl et al., 1998; Fast and Easter, 2006) was used to generate $72 \mathrm{~h}$ backward dispersions around the Beijing area. 50000 particles were released backwards from a box $\left(1^{\circ} \times 1^{\circ} \times 400 \mathrm{~m}\right)$, the center of which is Beijing urban area, from 19 January 00:00. The number concentrations of particles were plotted at $6 \mathrm{~h}$ before, $12 \mathrm{~h}$ before, $24 \mathrm{~h}$ before and $48 \mathrm{~h}$ before the released time (Fig. 12). For $12 \mathrm{~h}$, Beijing was influenced by sources to the south, including sources from south Hebei, Tianjin and Shandong. For 2 days, more sources contributed to the haze buildup in Beijing, including sources from Henan and Inner Mongolia. A number of coal mines are located in Hebei, Shandong and Henan provinces and Inner Mongolia areas have high emissions of primary aerosols.

\subsection{The impact of aerosol feedback}

Aerosols affect weather and climate through many pathways, including reducing downward solar radiation through absorption and scattering (direct effect), changing temperature, wind speed, RH and atmospheric stability due to absorption by absorbing aerosols (semi-direct effect), serving as cloud condensation nuclei $(\mathrm{CCN})$ and thus impacting optical properties of clouds (first indirect effect), and affecting cloud coverage, lifetime of clouds and precipitation (second indirect effect; Zhang et al., 2010; Forkel et al., 2012). The feedback mechanisms are complex and many aspects of them are not well understood. Although previous studies have investigated aerosol-radiation-meteorology interactions (Zhang et al., 2010; Forkel et al., 2012), the studies on short timescale events with high aerosol loadings, such as haze events, are limited. This section focuses on evaluating the impacts of aerosol feedback mechanism on meteorology and air quality. The feedback discussed in this paper only includes aerosols' direct and semi-direct effects.

\subsubsection{Impact of feedback on meteorology and $\mathrm{PM}_{2.5}$ distribution}

Figure 13a shows the observed daily maximum surface solar radiation and simulated surface solar radiation for the with feedback (WF) and without feedback (NF) scenarios in Beijing. Simulated daily maximum surface shortwave radiation values for the NF scenario are higher than observations and the overestimations are reduced by implementing aerosol feedback (Fig. 13a). For the NF case, the correlation coefficient $\mathrm{R}$ between simulated and observed daily maximum surface shortwave radiation is 0.84 in Beijing; for the WF scenario, the correlation coefficient increased to $R=0.93$, and the haze reduced the shortwave radiation values by 30 to $80 \%$.

The changes in radiation have impacts on the environment. Simulated PBLH and $\mathrm{PM}_{2.5}$ concentration at Shijiazhuang for the WF and NF scenarios are shown in Fig. 13b and c. In non-haze days, PBLH differences between the two scenarios are negligible due to low aerosol loadings. In haze days, PBLHs in the WF scenario are generally lower (by up to $60 \%$ ) than in the NF scenario. As shown in Fig. 13c, $\mathrm{PM}_{2.5}$ concentration at Shijiazhuang in WF scenario is higher than it is in the NF scenario and the difference reaches about $50 \mu \mathrm{g} \mathrm{m}^{-3}$ on 19 January. Aerosols affect PBLHs in two ways: (1) radiation is scattered back to sky and absorbed, and as a result, radiation reaching the surface is reduced (Fig. 13a) and temperature is lowered; and (2) suspended 

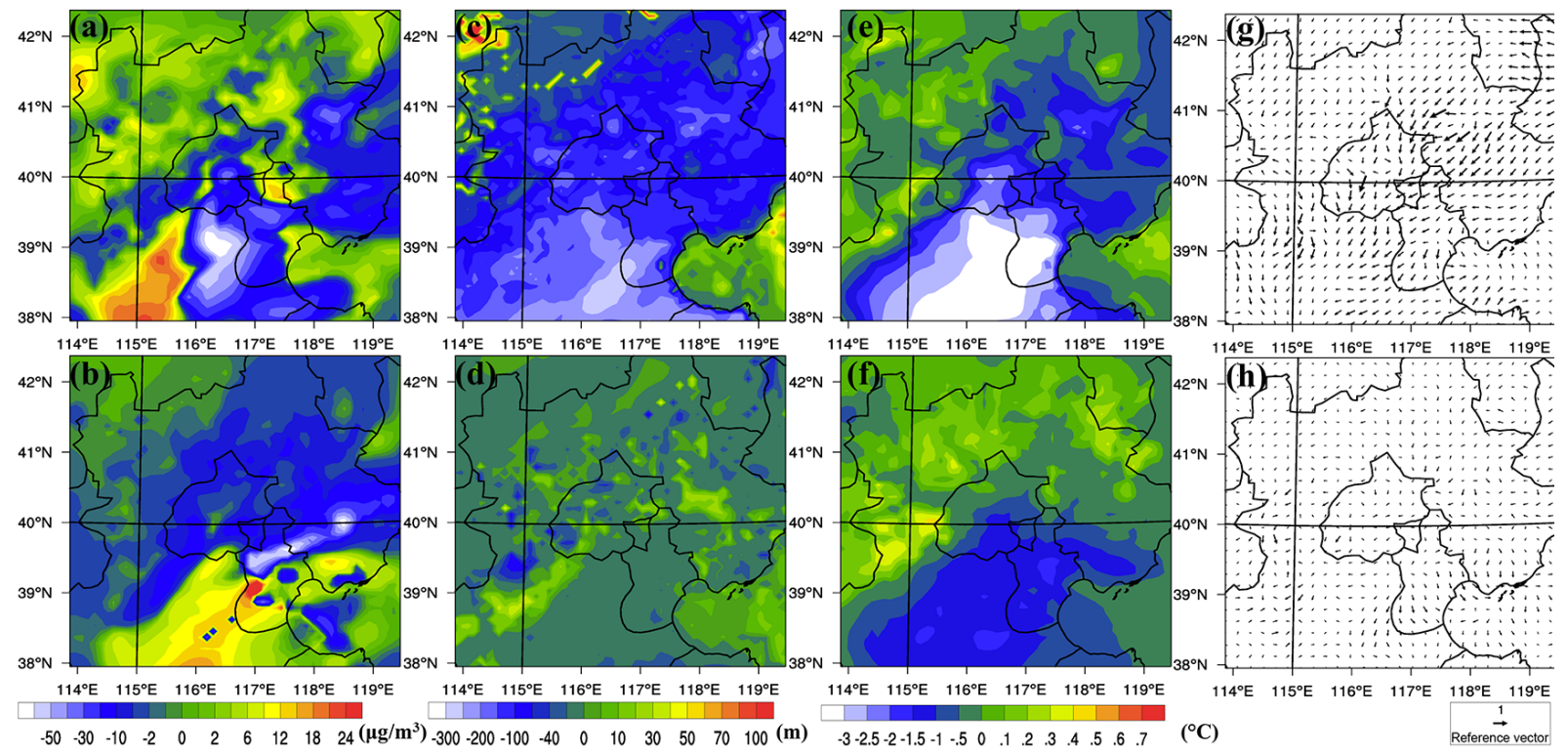

Figure 15. Differences of $\mathrm{PM}_{2.5}$ concentration (unit: $\mu \mathrm{g} \mathrm{m}^{-3}$ ), temperature (unit: ${ }^{\circ} \mathrm{C}$ ), $\mathrm{PBLH}$ (unit: $\mathrm{m}$ ) and horizontal wind (unit: $\mathrm{m} \mathrm{s}^{-1}$ ) at 02:00 p.m. (a, c, e, g) and 02:00 a.m. (b, d, f, h) between WF and NF scenarios.

aerosols like $\mathrm{BC}$ absorb radiation to heat the upper PBL (Ding et al., 2013). Both of these ways increase temperature inversion and atmospheric stability, and thus exacerbate $\mathrm{PM}_{2.5}$ pollution.

Figure 14 shows temporal variations of vertical profiles of (a) $\mathrm{PM}_{2.5}$ (c) $\mathrm{RH}$ (e) temperature (g) wind speeds differences in Beijing between WF and NF scenarios. When aerosol feedback is included, $\mathrm{PM}_{2.5}$ concentrations near Beijing surface are mostly increased, except on the morning of 17 January on the afternoon of 18 and on 19 January (Fig. 14a). The increases of $\mathrm{PM}_{2.5}$ are caused by the above mentioned decrease of temperature gradient from surface to aloft (shown in Fig. 14e) and atmospheric stability. Apart from these, $\mathrm{PM}_{2.5}$ concentrations are also affected by $\mathrm{RH}$ and wind speeds. In WF scenario, RH is generally increased near the surface, especially on 19 January (Fig. 14c), while horizontal wind speeds are also increased on 19 January which is the main cause of decreases of $\mathrm{PM}_{2.5}$ concentrations in Beijing.

To evaluate the impact of aerosol feedback on horizontal meteorological fields and $\mathrm{PM}_{2.5}$ distributions, averaged differences of $\mathrm{PM}_{2.5}$ concentrations, temperature, PBLHs and horizontal winds between WF and NF scenarios at 02:00 p.m. and 02:00 a.m. in haze days (from 16 to 19 January) were calculated and are shown in Fig. 15. Figure 15c shows that PBLHs are reduced in almost all NCP areas when aerosol feedbacks are considered at 02:00 p.m. At 02:00 p.m. $\mathrm{PM}_{2.5}$ concentrations increase about $21.9 \mathrm{\mu g} \mathrm{m}^{-3}$ at Shijiazhuang $\left(114.53^{\circ} \mathrm{E}, 38.03^{\circ} \mathrm{N}\right)$. In a few locations (the areas to the south of Beijing (Fig. 15a), PM levels decrease although PBLHs are suppressed in those areas. The decreases of $\mathrm{PM}_{2.5}$ concentrations in the areas south of Beijing are due to big horizontal wind changes, shown in Fig. 15g. When aerosol feedback is included, surface temperature decreases in areas where there are high aerosol loadings (Fig. 15e). Figure 15d shows that PBLHs are enhanced in east and southwest NCP areas at 02:00 a.m. with aerosol feedback. Aerosol feedback mechanism at night time is more complex compared to it at day time. At night, there is no incoming shortwave radiation from the sun and major radiation is the long wave radiation emitted from the earth. The presence of clouds and some kinds of aerosols can trap outgoing long wave radiation, and as a result, the surface atmosphere is warmed. Different aerosols show different effects on long wave radiation. Greenhouse gases (GHGs) absorb long wave radiation, while large particles like dust scatter long wave radiation. As a result, the upper atmosphere temperature is likely to be warmer or cooler than surface atmosphere temperature. If the upper atmosphere is warmer than the surface, a stable PBL will form. This can explain why aerosol feedbacks increase PBL heights in some regions and decrease in some other regions of NCP. Changes of $\mathrm{PM}_{2.5}$ concentrations at 2a.m. are mainly caused by changed PBLHs (Fig. 15b), showing decreasing trends in areas where PBLHs are enhanced, because changes of winds are relatively small (Fig. 15h). Temperature changes at 02:00 a.m. are similar to it at 02:00 p.m., but the magnitudes are smaller.

\subsubsection{Impact of $\mathrm{BC}$ absorption on meteorology and $\mathbf{P M}_{2.5}$ distribution}

To investigate BC's influence on meteorology and air quality, sensitivity tests were conducted by removing $\mathrm{BC}$ absorption in WRF-Chem (i.e., imaginary refractive index set to zero). 

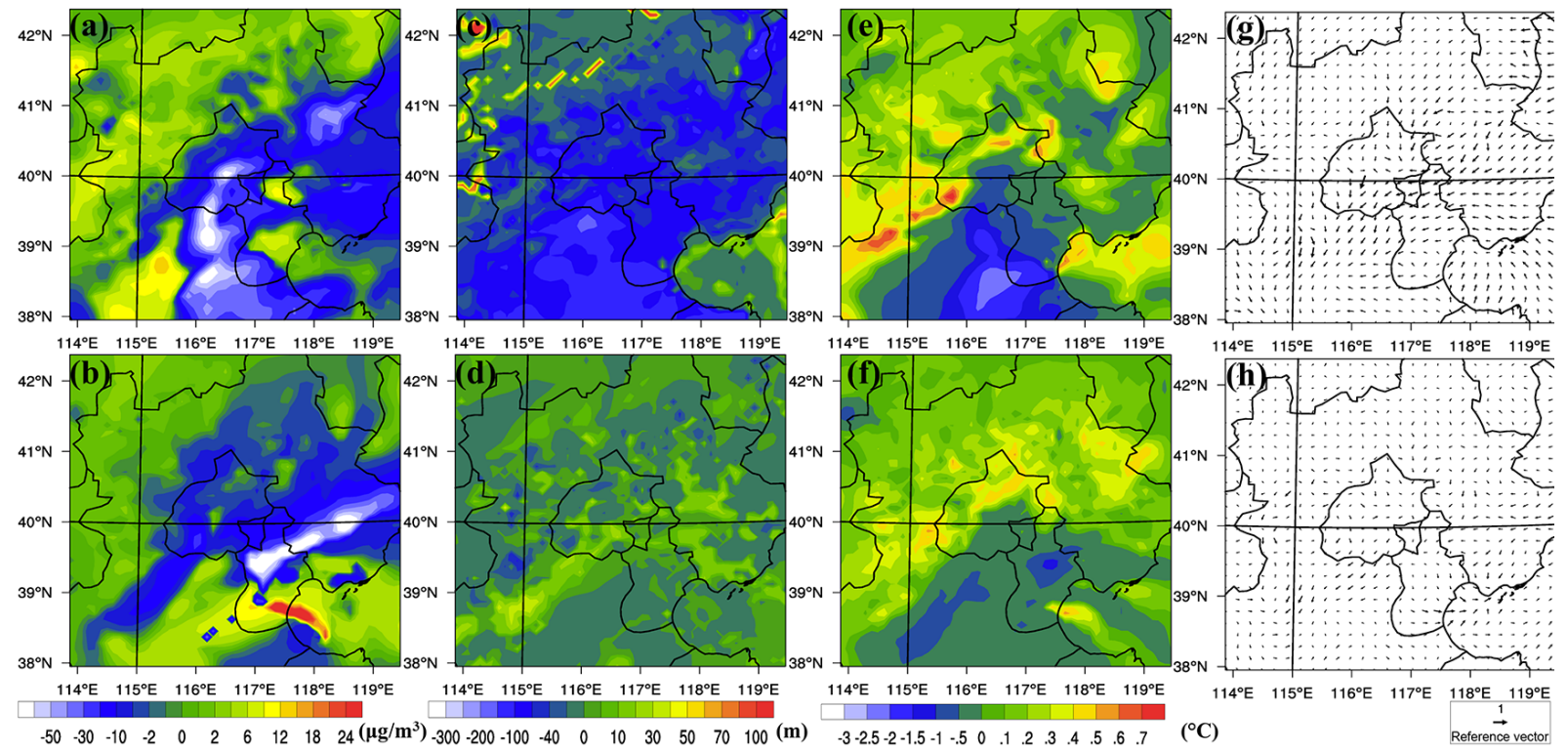

Figure 16. Differences of $\mathrm{PM}_{2.5}$ concentration (unit: $\mu \mathrm{g} \mathrm{m}^{-3}$ ), temperature (unit: ${ }^{\circ} \mathrm{C}$ ), $\mathrm{PBLH}$ (unit: $\mathrm{m}$ ) and horizontal wind (unit: $\mathrm{m} \mathrm{s}^{-1}$ ) at 02:00 p.m. (a, c, e, g) and 02:00 a.m. (b, d, f, h) between WF and NBCA scenarios.

Figure 14 shows temporal variations of vertical profiles of (b) $\mathrm{PM}_{2.5}$ (d) $\mathrm{RH}$ (f) temperature and (h) wind speeds differences in Beijing between WF and NBCA scenarios. The differences between WF and NBCA can be used to represent impacts of $\mathrm{BC}$ absorption since in WF scenario both scattering and absorbing are considered while in the NBCA scenario only scattering is considered. It is obvious from Fig. 14f that the upper atmosphere is heated by BC, especially at $1.5 \mathrm{~km}$, which increases temperature inversion and atmospheric stability. BC absorption's impacts on $\mathrm{PM}_{2.5}$, RH and wind speeds are similar to the impacts of both scattering and absorption, but the magnitudes are smaller (Fig. 14b, d and $\mathrm{g}$ ).

Figure 16 is similar to Fig. 15 except that the differences are between WF and NBCA scenarios. At 02:00 p.m., $\mathrm{PM}_{2.5}$ concentration is increased by about $14.4 \mu \mathrm{g} \mathrm{m}^{-3}$ in Shijiazhuang $\left(114.53^{\circ} \mathrm{E}, 38.03^{\circ} \mathrm{N}\right)$, accounting for about $65.7 \%$ of $\mathrm{PM}_{2.5}$ changes due to the total aerosol feedback (Fig. 16a). At 02:00 p.m., the maximum decrease in PBLH is about $166.6 \mathrm{~m}$ (Fig. 16c), accounting for about $59.9 \%$ of the maximum decrease in PBLH in Fig. 15c. At 02:00 p.m., surface temperature in high aerosol loading areas are decreased by about $0-2{ }^{\circ} \mathrm{C}$ (Fig. 16e), while the temperature decreases in the same areas are above $2{ }^{\circ} \mathrm{C}$ in Fig. 16e. At 02:00 a.m., changes of $\mathrm{PM}_{2.5}$, PBLHs, surface temperature and wind speeds are similar to Fig. 15, with smaller magnitudes.

The contribution of $\mathrm{BC}$ absorption in aerosol feedbacks depends on the model performance in simulating $\mathrm{BC}$ and scattering aerosols (sulfate, OC). As shown in Fig. 11, BC was overestimated, and sulfate and $\mathrm{OC}$ were underestimated in Beijing. The overestimation could be as large as a factor of 2 in some days. As a result, the relative contributions of
$\mathrm{BC}$ absorption in aerosol feedbacks are uncertain. To explore the uncertainties of the $\mathrm{BC}$ absorption contribution, we conducted a simulation by reducing $\mathrm{BC}$ emissions by $50 \%$. The changes of PBLH and $\mathrm{PM}_{2.5}$ concentrations at 02:00 p.m. due to aerosol feedbacks and BC absorption after BC emission changes are shown in Fig. 17. The domain maximum increases of $\mathrm{PM}_{2.5}$ concentrations because of aerosol feedbacks and BC absorption are 19.1 and $10.2 \mu \mathrm{g} \mathrm{m}^{-3}$, respectively for the base and $50 \% \mathrm{BC}$ emission cases. The domain maximum decreases of PBLH due to aerosol feedbacks and $\mathrm{BC}$ absorption are 235.7 and $114.2 \mathrm{~m}$, respectively. These numbers are smaller than before because $\mathrm{BC}$ emissions were reduced by $50 \%$. Due to $50 \%$ perturbation in $\mathrm{BC}$ emissions, the contribution of $\mathrm{BC}$ absorption in aerosol feedbacks decreased from about 60 to $50 \%$. This number can be additionally reduced if $\mathrm{OC}$ and sulfate concentrations are simulated well. These calculations suggest that the contributions of BC absorption to the aerosol feedbacks are significant, but there remain large uncertainties in the absolute magnitude. In the future, we can get more accurate estimations of BC absorption in aerosol feedbacks after the performances of simulating $\mathrm{BC}, \mathrm{OC}$ and sulfate are improved.

\section{Conclusions}

In this study, the online coupled WRF-Chem model was used to reproduce the haze event which happened in January 2010 in the NCP. The model was evaluated against multiple observations, including surface observations of meteorological variables and air pollutants, atmospheric sounding products, surface AOD measurements, and satellite AOD 


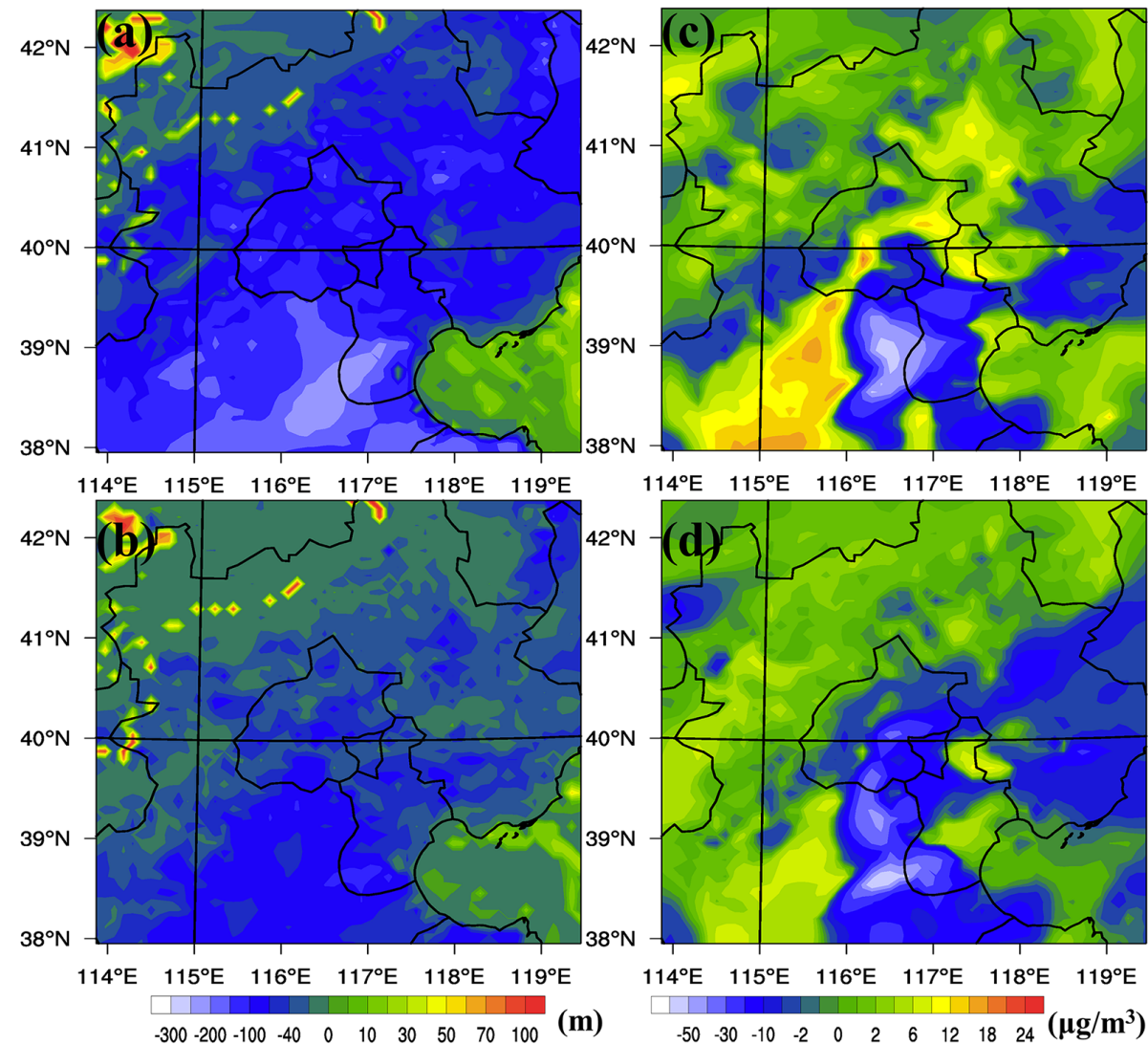

Figure 17. Differences of PBLH (unit: $\mathrm{m}$ ) and $\mathrm{PM}_{2.5}$ concentration (unit: $\mu \mathrm{g} \mathrm{m}^{-3}$ ) at 02:00 p.m. between WF and NF scenarios (a, c) when $\mathrm{BC}$ emissions were reduced by half; differences of PBLH (unit: $\mathrm{m}$ ) and $\mathrm{PM}_{2.5}$ concentration (unit: $\mu \mathrm{g} \mathrm{m}^{-3}$ ) at 02:00 p.m. between WF and NF scenarios $(\mathbf{b}, \mathbf{d})$ when $\mathrm{BC}$ emissions were reduced by half.

measurements. The correlation coefficients between simulated and observed $\mathrm{PM}_{2.5}$ concentrations in Beijing, Tianjin and Xianghe stations are $0.77,0.75$ and 0.69 , indicating that WRF-Chem provides reliable representation for the 2010 haze event in the NCP.

This haze event is mainly caused by high emissions of air pollutants in the NCP region and stable weather conditions in winter. The haze built up almost simultaneously in major cities in the NCP and dissipated from north to south. During haze days, horizontal wind speeds and mixing heights were low, temperature inversion happened above surface and RH values were above $40 \%$. Photochemistry was not significant during haze days due to weak UV radiation. In addition, secondary inorganic aerosols played an important role in the haze event. The role of cloud chemistry in this haze event cannot be ignored.

The contribution of non-local sources to $\mathrm{PM}_{2.5}$ in Beijing was also studied. The average contribution was about $64.5 \%$ in haze days. The FLEXPART model was implemented to investigate the sources of the non-local contributions and results show that air pollutants from south Hebei, Tianjin city, Shandong and Henan provinces are the major contributors to the $\mathrm{PM}_{2.5}$ in Beijing.
Impacts of high aerosols in haze days on radiation, boundary layer heights and $\mathrm{PM}_{2.5}$ have been demonstrated. When aerosol feedback is considered, simulated surface radiation agrees well with observations. In haze days, aerosol feedback has important impacts on surface temperature, $\mathrm{RH}$ and wind speeds, and these meteorological variables affect aerosol distribution and formation in turn. The role of $\mathrm{BC}$ in aerosol feedback loop has also been investigated. The model sensitivity studies showed that BC absorption has significant impacts on meteorology and air quality. Therefore, more attention should be paid to $\mathrm{BC}$ from both air pollution control and climate change perspectives. However the uncertainties remain large and further studies are needed to better quantify the role of absorption in the feedbacks.

\section{The Supplement related to this article is available online at doi:10.5194/acp-16-1673-2016-supplement.}

Acknowledgements. Special thanks are given to Yuesi Wang, Jinyuan Xin and their research groups for providing measurements to evaluate model performance. The ground observation 
was supported by the National Natural Science Foundation of China (41222033; 41375036) and the CAS Strategic Priority Research Program Grant (XDA05100102, XDB05020103). We also would like to thank Yafang Cheng for her contributions to the development of emission processing model. The NCEP FNL data were available at http://rda.ucar.edu/datasets/ds083.2/. The MEIC emission inventory data are obtained from http://www.meicmodel.org/. The MOZART-4 chemical data are available at http://www.acd.ucar.edu/wrf-chem/mozart.shtml. Contact M. Gao (meng-gao@uiowa.edu) or G. R. Carmichael (gcarmich@engineering.uiowa.edu) for data requests.

Edited by: J. West

\section{References}

Ackermann, I. J., Hass, H., Memmesheimer, M., Ebel, A., Binkowski, F. S., and Shankar, U. M. A.: Modal aerosol dynamics model for Europe: development and first applications, Atmos. Environ., 32, 2981-2999, 1998.

Boylan, J. W. and Russell, A. G.: PM and light extinction model performance metrics, goals, and criteria for threedimensional air quality models, Atmos. Environ., 40, 49464959, doi:10.1016/j.atmosenv.2005.09.087, 2006.

Chapman, E. G., Gustafson Jr., W. I., Easter, R. C., Barnard, J. C., Ghan, S. J., Pekour, M. S., and Fast, J. D.: Coupling aerosolcloud-radiative processes in the WRF-Chem model: Investigating the radiative impact of elevated point sources, Atmos. Chem. Phys., 9, 945-964, doi:10.5194/acp-9-945-2009, 2009.

Chen, X.-L., Feng, Y.-R., Li, J.-N., Lin, W.-S., Fan, S.-J., Wang, A.-Y., Fong, S., and Lin, H.: Numerical simulations on the effect of sea-land breezes on atmospheric haze over the Pearl River Delta Region, Environ. Model. Assess., 14, 351-363, doi:10.1007/s10666-007-9131-5, 2007.

Cheng, Y., Engling, G., He, K.-B., Duan, F.-K., Ma, Y.-L., Du, Z.Y., Liu, J.-M., Zheng, M., and Weber, R. J.: Biomass burning contribution to Beijing aerosol, Atmos. Chem. Phys., 13, 77657781, doi:10.5194/acp-13-7765-2013, 2013.

Cheng, Z., Wang, S., Fu, X., Watson, J. G., Jiang, J., Fu, Q., Chen, C., Xu, B., Yu, J., Chow, J. C., and Hao, J.: Impact of biomass burning on haze pollution in the Yangtze River delta, China: a case study in summer 2011, Atmos. Chem. Phys., 14, 45734585, doi:10.5194/acp-14-4573-2014, 2014.

Chou, M.-D., Suarez, M. J., Ho, C.-H., Yan, M. M.-H. and Lee, K.-T.: Parameterizations for cloud overlapping and shortwave single-scattering properties for use in general circulation and cloud ensemble models, J. Climate, 11, 202-214, 1998.

Ding, A. J., Fu, C. B., Yang, X. Q., Sun, J. N., Petäjä, T., Kerminen, V.-M., Wang, T., Xie, Y., Herrmann, E., Zheng, L. F., Nie, W., Liu, Q., Wei, X. L., and Kulmala, M.: Intense atmospheric pollution modifies weather: a case of mixed biomass burning with fossil fuel combustion pollution in eastern China, Atmos. Chem. Phys., 13, 10545-10554, doi:10.5194/acp-13-10545-2013, 2013.

Emery, C., Tai, E., and Yarwood, G.: Enhanced meteorological modeling and performance evaluation for two Texas ozone episodes, in: Prepared for the Texas Natural Resource Conservation Commission, ENVIRON International Corporation, Novato, CA, USA, 2001.
Emmons, L. K., Walters, S., Hess, P. G., Lamarque, J.-F., Pfister, G. G., Fillmore, D., Granier, C., Guenther, A., Kinnison, D., Laepple, T., Orlando, J., Tie, X., Tyndall, G., Wiedinmyer, C., Baughcum, S. L., and Kloster, S.: Description and evaluation of the Model for Ozone and Related chemical Tracers, version 4 (MOZART-4), Geosci. Model Dev., 3, 43-67, doi:10.5194/gmd3-43-2010, 2010.

Fast, J. D. and Easter, R. C.: A Lagrangian Particle Dispersion Model Compatible with WRF, in 7th Annual WRF User's Workshop, 19-22 June 2006, Boulder, CO, USA, P6.2, available at: http://www2.mmm.ucar.edu/wrf/users/workshops/ WS2006/abstracts/PSession06/P6_02_Fast.pdf (last access: 1 June 2015), 2006.

Fast, J. D., Gustafson, W. I., Easter, R. C., Zaveri, R. A., Barnard, J. C., Chapman, E. G., Grell, G. A., and Peckham, S. E.: Evolution of ozone, particulates, and aerosol direct radiative forcing in the vicinity of Houston using a fully coupled meteorology-chemistry-aerosol model, J. Geophys. Res.-Atmos., 111, D21305, doi:10.1029/2005JD006721, 2006.

Forkel, R., Werhahn, J., Hansen, A. B., McKeen, S., Peckham, S., Grell, G., and Suppan, P.: Effect of aerosol-radiation feedback on regional air quality - a case study with WRF/Chem, Atmos. Environ., 53, 202-211, doi:10.1016/j.atmosenv.2011.10.009, 2012.

Gao, M., Guttikunda, S. K., Carmichael, G. R.,Wang, Y., Liu, Z., Stanier, C. O., Saide, P. E., and Yu, M.: Health impacts and economic losses assessment of the 2013 severe haze event in Beijing area, Sci. Total Environ., 511, 553-561, doi:10.1016/j.scitotenv.2015.01.005, 2015.

Guenther, A., Karl, T., Harley, P., Wiedinmyer, C., Palmer, P. I., and Geron, C.: Estimates of global terrestrial isoprene emissions using MEGAN (Model of Emissions of Gases and Aerosols from Nature), Atmos. Chem. Phys., 6, 3181-3210, doi:10.5194/acp-63181-2006, 2006.

Guo, S., Hu, M., Zamora, M. L., Peng, J., Shang, D., Zheng, J., Du, Z., Wu, Z., Shao, M., Zeng, L., Molina, M. J., and Zhang, R.: Elucidating severe urban haze formation in China, P. Natl. Acad. Sci. USA, 111, 17373-17378, doi:10.1073/pnas.1419604111, 2014.

Han, S., Wu, J., Zhang, Y., Cai, Z., Feng, Y., Yao, Q., Li, X., Liu, Y., and Zhang, M.: Characteristics and formation mechanism of a winter haze-fog episode in Tianjin, China, Atmos. Environ., 98, 323-330, doi:10.1016/j.atmosenv.2014.08.078, 2014.

Han, X., Zhang, M., Gao, J., Wang, S., and Chai, F.: Modeling analysis of the seasonal characteristics of haze formation in Beijing, Atmos. Chem. Phys., 14, 10231-10248, doi:10.5194/acp14-10231-2014, 2014.

He, H., Tie, X., Zhang, Q., Liu, X., Gao, Q., Li, X., and Gao, Y.: Analysis of the causes of heavy aerosol pollution in Beijing, China: a case study with the WRF-Chem model, Particuology, 20, 32-40, doi:10.1016/j.partic.2014.06.004, 2014a.

He, H., Wang, Y., Ma, Q., Ma, J., Chu, B., Ji, D., Tang, G., Liu, C., Zhang, H., and Hao, J.: Mineral dust and $\mathrm{NO}_{x}$ promote the conversion of $\mathrm{SO}_{2}$ to sulfate in heavy pollution days, Sci. Rep., 4, 4172, doi:10.1038/srep04172, 2014b.

Hong, S.-Y., Noh, Y., and Dudhia, J.: A New Vertical Diffusion Package with an Explicit Treatment of Entrainment Processes, Mon. Weather Rev., 134, 2318-2341, 2006.

Huang, K., Zhuang, G., Wang, Q., Fu, J. S., Lin, Y., Liu, T., Han, L., and Deng, C.: Extreme haze pollution in Beijing during January 2013: chemical characteristics, formation mechanism and role of 
fog processing, Atmos. Chem. Phys. Discuss., 14, 7517-7556, doi:10.5194/acpd-14-7517-2014, 2014.

Huang, X., Song, Y., Zhao, C., Li, M., Zhu, T., Zhang, Q., and Zhang, X.: Pathways of sulfate enhancement by natural and anthropogenic mineral aerosols in China, J. Geophys. Res.-Atmos., 119, 14165-14179, doi:10.1002/2014JD022301, 2014.

Jiang, F., Liu, Q., Huang, X., Wang, T., Zhuang, B., and Xie, M.: Regional modeling of secondary organic aerosol over China using WRF/Chem, J. Aerosol Sci., 43, 57-73, doi:10.1016/j.jaerosci.2011.09.003, 2012.

Li, P., Yan, R., Yu, S., Wang, S., Liu, W., and Bao, H.: Reinstate regional transport of $\mathrm{PM}_{2.5}$ as a major cause of severe haze in Beijing, P. Natl. Acad. Sci. USA, 112, E2739-E2740, doi:10.1073/pnas.1502596112, 2015.

Li, W. J., Shao, L. Y., and Buseck, P. R.: Haze types in Beijing and the influence of agricultural biomass burning, Atmos. Chem. Phys., 10, 8119-8130, doi:10.5194/acp-10-8119-2010, 2010.

Li, Z., Gu, X., Wang, L., Li, D., Xie, Y., Li, K., Dubovik, O., Schuster, G., Goloub, P., Zhang, Y., Li, L., Ma, Y., and Xu, H.: Aerosol physical and chemical properties retrieved from ground-based remote sensing measurements during heavy haze days in Beijing winter, Atmos. Chem. Phys., 13, 10171-10183, doi:10.5194/acp13-10171-2013, 2013.

Lin, Y.-L., Farley, R. D., and Orville, H. D.: Bulk parameterization of the snow field in a cloud model, J. Clim. Appl. Meteorol., 22, 1065-1092, 1983.

Liu, X. G., Li, J., Qu, Y., Han, T., Hou, L., Gu, J., Chen, C., Yang, Y., Liu, X., Yang, T., Zhang, Y., Tian, H., and Hu, M.: Formation and evolution mechanism of regional haze: a case study in the megacity Beijing, China, Atmos. Chem. Phys., 13, 4501-4514, doi:10.5194/acp-13-4501-2013, 2013.

Mlawer, E. J., Taubman, S. J., Brown, P. D., Iacono, M. J., and Clough, S. A.: Radiative transfer for inhomogeneous atmospheres: RRTM, a validated correlated-k model for the longwave, J. Geophys. Res., 102, 16663-16682, doi:10.1029/97JD00237, 1997.

Morris, R. E., McNally, D. E., Tesche, T. W., Tonnesen, G., Boylan, J. W., and Brewer, P.: Preliminary evaluation of the community multiscale air quality model for 2002 over the southeastern United States, J. Air Waste Manage., 55, 1694-1708, doi:10.1080/10473289.2005.10464765, 2005.

Peng, C., Wu, X., Liu, G., Johnson, T., and Shah, J.: Urban air quality and health in China, Urban Stud., 39, 2283-2299, doi:10.1080/0042098022000033872, 2002.

Perez, P., Palacios, R., and Castillo, A.: Carbon monoxide concentration forecasting in Santiago, Chile, J. Air Waste Manage., 54, 908-913, doi:10.1080/10473289.2004.10470966, 2004.

Quan, J., Tie, X., Zhang, Q., Liu, Q., Li, X., Gao, Y., and Zhao, D.: Characteristics of heavy aerosol pollution during the 20122013 winter in Beijing, China, Atmos. Environ., 88, 83-89, doi:10.1016/j.atmosenv.2014.01.058, 2014.

Saide, P. E., Carmichael, G. R., Spak, S. N., Gallardo, L., Osses, A. E., Mena-Carrasco, M. A., and Pagowski, M.: Forecasting urban $\mathrm{PM}_{10}$ and $\mathrm{PM}_{2.5}$ pollution episodes in very stable nocturnal conditions and complex terrain using WRFChem CO tracer model, Atmos. Environ., 45, 2769-2780, doi:10.1016/j.atmosenv.2011.02.001, 2011.

Schell, B., Ackermann, I. J., Hass, H., and Carolina, N.: Modeling the formation of secondary organic aerosol within a compre- hensive air quality model system, J. Geophys. Res., 106, 2827528293, 2001.

Schuster, G. L., Dubovik, O., and Holben, B. N.: Angstrom exponent and bimodal aerosol size distributions, J. Geophys. Res., 111, D07207, doi:10.1029/2005JD006328, 2006.

Stockwell, W. R., Middleton, P., and Chang, J. S.: The second generation regional acid deposition model chemical mechanism for regional air quality modeling, J. Geophys. Res., 95, 16343-16367, 1990.

Stohl, A., Hittenberger, M., and Wotawa, G.: Validation of the lagrangian particle dispersion model FLEXPART against largescale tracer experiment data, Atmos. Environ., 32, 4245-4264, doi:10.1016/S1352-2310(98)00184-8, 1998.

Sun, Y., Zhuang, G., Tang, A. A., Wang, Y., and An, Z.: Chemical characteristics of $\mathrm{PM}_{2.5}$ and $\mathrm{PM}_{10}$ in haze-fog episodes in Beijing, Environ. Sci. Technol., 40, 3148-3155, 2006.

Sun, Y., Jiang, Q., Wang, Z., Fu, P., Li, J., Yang, T., and Yin, Y.: Investigation of the sources and evolution processes of severe haze pollution in Beijing in January 2013, J. Geophys. Res.-Atmos., 119, 4380-4398, doi:10.1002/2014JD021641, 2014.

Tan, J.-H., Duan, J.-C., Chen, D.-H., Wang, X.-H., Guo, S.-J., Bi, X.-H., Sheng, G.-Y., He, K.-B., and Fu, J.-M.: Chemical characteristics of haze during summer and winter in Guangzhou, Atmos. Res., 94, 238-245, doi:10.1016/j.atmosres.2009.05.016, 2009.

Tao, M., Chen, L., Su, L., and Tao, J.: Satellite observation of regional haze pollution over the North China Plain, J. Geophys. Res. Atmos., 117, D12203, doi:10.1029/2012JD017915, 2012.

Tao, M., Chen, L., Xiong, X., Zhang, M., Ma, P., Tao, J., and Wang, Z.: Formation process of the widespread extreme haze pollution over northern China in January 2013: Implications for regional air quality and climate, Atmos. Environ., 98, 417-425, 10 doi:10.1016/j.atmosenv.2014.09.026, 2014.

Tuccella, P., Curci, G., Visconti, G., Bessagnet, B., Menut, L., and Park, R. J.: Modeling of gas and aerosol with WRF/Chem over Europe: Evaluation and sensitivity study, J. Geophys. Res., 117, D03303, doi:10.1029/2011JD016302, 2012.

Wang, G., Kawamura, K., Xie, M., Hu, S., Cao, J., An, Z., Waston, J. G., and Chow, J. C.: Organic molecular compositions and size distributions of Chinese summer and autumn aerosols from Nanjing: characteristic haze event caused by wheat straw burning, Environ. Sci. Technol., 43, 6493-6499, 2009.

Wang, J., Wang, S., Jiang, J., Ding, A., Zheng, M., Zhao, B., Wong, D. C., Zhou, W., Zheng, G.,Wang, L., Pleim, J. E., and Hao, J.: Impact of aerosol-meteorology interactions on fine particle pollution during China's severe haze episode in January 2013, Environ. Res. Lett., 9, 094002, doi:10.1088/1748-9326/9/9/094002, 2014.

Wang, L., Xu, J., Yang, J., Zhao, X., Wei,W., Cheng, D., Pan, X., and $\mathrm{Su}$, J.: Understanding haze pollution over the southern Hebei area of China using the CMAQ model, Atmos. Environ., 56, 6979, doi:10.1016/j.atmosenv.2012.04.013, 2012.

Wang, L. T., Wei, Z., Yang, J., Zhang, Y., Zhang, F. F., Su, J., Meng, C. C., and Zhang, Q.: The 2013 severe haze over southern Hebei, China: model evaluation, source apportionment, and policy implications, Atmos. Chem. Phys., 14, 3151-3173, doi:10.5194/acp-14-3151-2014, 2014.

Wang, Q., Shao, M., Liu, Y., William, K., Paul, G., Li, X., Liu, Y., and Lu, S.: Impact of biomass burning on ur- 
ban air quality estimated by organic tracers: Guangzhou and Beijing as cases, Atmos. Environ., 41, 8380-8390, doi:10.1016/j.atmosenv.2007.06.048, 2007.

Wang, Y., Yao, L., Wang, L., Liu, Z., Ji, D., Tang, G., Zhang, J., Sun, Y., Hu, B., and Xin, J.: Mechanism for the formation of the January 2013 heavy haze pollution episode over central and eastern China, Sci. China Earth Sci., 57, 14-25, doi:10.1007/s11430013-4773-4, 2014a.

Wang, Y., Zhang, Q., Jiang, J., Zhou, W., Wang, B., He, K., Duan, F., Zhang, Q., Philip, S., and Xie, Y.: Enhanced sulfate formation during China's severe winter haze episode in January 2013 missing from current models, J. Geophys. Res.-Atmos., 119, 1042510440, doi:10.1002/2013JD021426, 2014b.

Wang, Z., Li, J., Wang, Z., Yang, 5 W., Tang, X., Ge, B., Yan, P., Zhu, L., Chen, X., Chen, H., Wand, W., Li, J., Liu, B., Wang, X., Zhao, Y., Lu, N., and Su, D.: Modeling study of regional severe hazes over mid-eastern China in January 2013 and its implications on pollution prevention and control, Sci. China Earth Sci., 57, 3-13, doi:10.1007/s11430-013-4793-0, 2014.

Watson, J. G.: Visibility: science and regulation, J. Air Waste Manage. Assoc., 52, 628-713, doi:10.1080/10473289.2002.10470813, 2002.

Willmott, C. J. and Matsuura, K.: Advantages of the mean absolute error (MAE) over the root mean square error (RMSE) in assessing average model performance, Clim. Res., 30, 79-82, 2005.

Yang, F., Tan, J., Zhao, Q., Du, Z., He, K., Ma, Y., Duan, F., Chen, G., and Zhao, Q.: Characteristics of $\mathrm{PM}_{2} .5$ speciation in representative megacities and across China, Atmos. Chem. Phys., 11, 5207-5219, doi:10.5194/acp-11-5207-2011, 2011.

Yu, M., Carmichael, G. R., Zhu, T., and Cheng, Y.: Sensitivity of predicted pollutant levels to urbanization in China, Atmos. Environ., 60, 544-554, doi:10.1016/j.atmosenv.2012.06.075, 2012.

Yu, X., Zhu, B., Yin, Y., Yang, J., Li, Y., and Bu, X.: A comparative analysis of aerosol properties in dust and haze-fog days in a Chinese urban region, Atmos. Res., 99, 241-247, doi:10.1016/j.atmosres.2010.10.015, 2011.

Zaveri, R. A. and Peters, L. K.: A new lumped structure photochemical mechanism for large-scale applications, J. Geophys. Res., 104, 30387-30415, doi:10.1029/1999JD900876,25 1999.
Zaveri, R. A., Easter, R. C., Fast, J. D., and Peters, L. K.: Model for Simulating Aerosol Interactions and Chemistry (MOSAIC), J. Geophys. Res., 113, D13204, doi:10.1029/2007JD008782, 2008.

Zhang, B., Wang, Y., and Hao, J.: Simulating aerosol-radiationcloud feedbacks on meteorology and air quality over eastern China under severe haze conditionsin winter, Atmos. Chem. Phys., 15, 2387-2404, doi:10.5194/acp-15-2387-2015, 2015.

Zhang, R., Guo, S., Zamora, M. L., and Hu, M.: Reply to Li et al.: Insucient evidence for the contribution of regional transport to severe haze formation in Beijing, P. Natl. Acad. Sci. USA, 112, E2741, doi:10.1073/pnas.1503855112, 2015.

Zhang, Y., Wen, X.-Y., and Jang, C. J.: Simulating chemistryaerosol-clou-radiation-climate feedbacks over the continental U.S. using the online-coupled Weather Research Forecasting Model with chemistry (WRF/Chem), Atmos. Environ., 44, 3568-3582, doi:10.1016/j.atmosenv.2010.05.056, 2010.

Zhang, Y., Chen, Y., Sarwar, G., and Schere, K.: Impact of gasphase mechanisms on Weather Research Forecasting Model with Chemistry (WRF/Chem) predictions: mechanism implementation and comparative evaluation, J. Geophys. Res., 117, D01301, doi:10.1029/2011JD015775, 2012.

Zhao, X. J., Zhao, P. S., Xu, J., Meng,, W., Pu, W. W., Dong, F., He, D., and Shi, Q. F.: Analysis of a winter regional haze event and its formation mechanism in the North China Plain, Atmos. Chem. Phys., 13, 5685-5696, doi:10.5194/acp-13-5685-2013, 2013.

Zheng, B., Zhang, Q., Zhang, Y., He, K. B., Wang, K., Zheng, G. J., Duan, F. K., Ma, Y. L., and Kimoto, T.: Heterogeneous chemistry: a mechanism missing in current models to explain secondary inorganic aerosol formation during the January 2013 haze episode in North China, Atmos. Chem. Phys., 15, 2031-2049, doi:10.5194/acp-15-2031-2015, 2015.

Zheng, G. J., Duan, F. K., Su, H., Ma, Y. L., Cheng, Y., Zheng, B., Zhang, Q., Huang, T., Kimoto, T., Chang, D., Pöschl, U., Cheng, Y. F., and He, K. B.: Exploring the severe winter haze in Beijing: the impact of synoptic weather, regional transport and heterogeneous reactions, Atmos. Chem. Phys., 15, 2969-2983, doi:10.5194/acp-15-2969-2015, 2015. 